\title{
Temporal Calibration of an Evaporation-Based Spatial Disaggregation Method of SMOS Soil Moisture Data
}

\author{
Vivien-Georgiana Stefan ${ }^{1, *}{ }^{\circledR}$, Olivier Merlin ${ }^{2}$, Maria-José Escorihuela ${ }^{1}\left(\mathbb{D}\right.$, Beatriz Molero ${ }^{2}$, \\ Jamal Chihrane ${ }^{3}$, Josep Maria Villar ${ }^{4}$ (D) and Salah Er-Raki ${ }^{5,6}$ (D) \\ 1 isardSAT, 08042 Barcelona, Spain; mj.escorihuela@isardSAT.cat \\ 2 CESBIO, Université de Toulouse, CNES/CNRS/IRD/UPS, 31400 Toulouse, France; \\ olivier.merlin@cesbio.cnes.fr (O.M.); bmolero@groupcls.com (B.M.) \\ 3 Centre National de Lutte Antiacridienne, Ait-Melloul (CNLAA), Inezgane, Agadir 86343, Morocco; \\ chihrane_61@yahoo.fr \\ 4 Department of Environment and Soil Sciences, Universitat de Lleida, 25003 Lleida, Spain; \\ jmvillar@macs.udl.cat \\ 5 LP2M2E, Faculté des Sciences et Techniques, Université Cadi Ayyad, Marrakech 40000, Morocco; \\ s.erraki@uca.ma \\ 6 Center for Remote Sensing Application (CRSA), Mohammed VI Polytechnic University, \\ Ben Guerir 43150, Morocco \\ * Correspondence: vivien.stefan@isardSAT.cat
}

Received: 31 March 2020; Accepted: 20 May 2020; Published: 23 May 2020

check for updates

Abstract: The resolution of current satellite surface soil moisture (SM) estimates is very low, of tens of kilometers, which proves to be insufficient for various agricultural and hydrological applications. Amongst the existing downscaling approaches of remotely sensed SM, DISPATCH (DISaggregation based on a Physical And Theoretical scale CHange) improves the resolution of SMOS (Soil Moisture and Ocean Salinity) soil moisture data using soil evaporative efficiency (SEE) estimates at high resolution (HR) and a SEE(SM) model implemented at low resolution (LR). Defined as the ratio of actual to potential soil evaporation, SEE can be derived from the remotely sensed land surface temperature (LST) and normalized difference vegetation index (NDVI). The current version of DISPATCH uses a linear SEE(SM) model. This study aims at improving the SEE(SM) model and testing different calibration strategies, to ultimately have more robust and better downscaled SM products. A nonlinear SEE(SM) model is introduced and its influence on the derived HR SM products is studied over a range of conditions. Each model, linear and nonlinear, is calibrated from remote sensing data on a daily and a multi-date basis. The approaches were tested over two mixed dry and irrigated areas in Catalonia, Spain, and over one dry area in Morocco. When using the linear model, better statistical results were generally obtained using a daily calibration (current version of DISPATCH), most notably over one Spanish site. However, the best results were systematically obtained for an annually calibrated nonlinear model, in terms of all metrics considered: correlation coefficient, slope of the linear regression, bias, unbiased root mean square error. In particular, when using the annually calibrated nonlinear SEE (SM) model, the temporal slope of the linear regression between disaggregated and in situ soil moisture increased to 1.16 and 0.75 for one Spanish site and for the Moroccan site (as opposed to 0.44 and 0.58, respectively, when using the linear model with a daily calibration). The temporal correlation coefficient increased to 0.47 and 0.54 over the Spanish sites (as opposed to 0.18 and 0.27, respectively, when using the linear model with a daily calibration). Those contrasted results indicate compensation effects between the model type and the calibration strategy. Taking into account studies that report the strong nonlinear behavior of the SEE with respect to SM, the introduction of the nonlinear SEE(SM) model in DISPATCH, combined with a multi-date calibration, is proven to perform significantly better under various conditions, leading to more robust disaggregated SM products. The SEE modeling based on the nonlinear SM model, with a multi-date calibration, could be integrated into the CATDS-Centre Aval 
de Traitement des Données SMOS as a future product, as well as into existing evapotranspiration models, which are based on a combination of thermal and microwave data.

Keywords: soil moisture; downscaling; disaggregation; SMOS; evaporation; MODIS

\section{Introduction}

Soil moisture (SM) is an essential hydrologic variable that impacts evaporation, infiltration and runoff, playing an important role in energy and carbon exchanges [1]. Its influence is assessed over a range of different scales: crop scale [2], hydrological scale [3], meteorological scale [4] and climatic scale [5]. Hence, the majority of hydrological and agricultural applications require high, at least at $1 \mathrm{~km}$, resolution SM data [6-8]. Surface SM observations are nowadays provided on a global basis using remote sensing data. Among all existing satellites, passive L-band microwave sensors are widely used to derive SM thanks to the strong physical link between the brightness temperature and the $0-5 \mathrm{~cm} \mathrm{SM}$ profile $[9,10]$. The downside to the operational retrieval of SM from microwave observations is given by the low resolution (LR) of the products, which ranges from 40 to $60 \mathrm{~km}[11,12]$, a resolution that is too coarse for most hydrological and agricultural applications $[13,14]$. Alternatively, optical/thermal sensors have the advantage of providing data at medium and high resolutions. In particular, Landsat and ASTER (Advanced Spaceborne Thermal Emission and Reflection radiometer) have resolutions of several tens of meters, while MODIS (MODerate Resolution Imaging Spectroradiometer) has a resolution ranging from 250 to $500 \mathrm{~m}$ and to $1 \mathrm{~km}$, depending on what band is used. Even though optical data could be used to derive $\mathrm{SM}$, the main drawback in deriving a retrieval methodology is given by the sensors' sensitivity to meteorological conditions (including cloud presence) [15-17] and vegetation cover $[15,18]$. More recently, the potential of Synthetic Aperture Radar (SAR) satellite data has also been investigated in deriving SM products. In particular, [19-21] have investigated the potential sensitivity of C-band and L-band SAR data with respect to SM, with results showing the higher potential of L-band over C-band, due to its higher penetration depth. The main advantage of using SAR data is the high resolution it provides (several tens of meters). However, the main drawback is that it is difficult to account for the soil roughness and the vegetation backscattering effect in the soil moisture retrieval modeling [20-22].

However, a synergy between the LR microwave and high resolution (HR) optical/thermal data [23] can be used in order to derive SM at various spatial scales. This is achieved by using the optical-derived land surface temperature (LST), which is linked to the soil water content and vegetation cover $[24,25]$. Most of the methods based on the synergy between microwave and optical data generally use the triangle [24] or trapezoid approach [26], in which the variations in LST are linked to variations in soil water content and vegetation cover $[27,28]$. The main hypotheses behind the triangle and trapezoid approaches are: (i) the only variability factors of the LST are the vegetation cover, surface SM and vegetation water stress, (ii) uniform meteorological conditions are met over the study area and (iii) the extreme temperatures can be correctly interpolated from the LST-NDVI (Normalized Difference Vegetation Index) space, which implies a heterogeneity of the surface conditions at the observation resolution [29,30]. As classified in [16] and in [17,31], there are various methodologies based on the synergy between microwave and optical data: polynomial fitting methods, evaporation-based methods, the UCLA method [32], the Peng method [33], thermal inertia-based methods [25,34,35]. The polynomial fitting methods [23,36], considered as purely empirical algorithms, use a polynomial function of LST, NDVI and surface albedo to express SM. Studies like [37-40] also take into account the brightness temperature in the polynomial fitting model in order to derive SM at 10 and $1 \mathrm{~km}$ resolutions from SMOS observations.

The evaporation-based methods are more theoretically and physically based than the polynomial fitting approach $[16,17]$. In these models, the evaporative fraction (EF) and/or the soil 
evaporative efficiency (SEE) are used as SM proxies, due to (i) keeping a constant value during the day [41,42], and (ii) their direct link to SM, while being independent on incoming radiation, as opposed to evapotranspiration or LST [43]. The SEE, defined as the ratio of actual to potential evaporation, can be derived either using microwave SM data or using optical data. Through its link with SEE, evaporation is the physical process that allows a link at multiple resolutions between the microwave SM and optical data. In particular, these models represent the spatial link between optical-derived SEE and surface SM. Their main advantages over the polynomial fitting methods are that (i) they are self-calibrated for each SMOS pixel individually, which fosters the validity of the hypothesis of meteorological uniformity even compared to methods implementing adaptive windows [40,44] and (ii) the average of the estimated HR SM is equal to the LR observed SM (meaning that the error residual as termed in [44] is zero).

Although the hypothesis of meteorological uniformity at large scale is difficult to be met by the methods based on the triangle or trapezoid models [44], recent studies have tackled that issue by introducing a self adaptive window in the downscaling methodology, which better meets the atmospheric forcing hypothesis. [44] have introduced a self-adaptive window in a downscaling method of SMAP SM and applied it over the Iberian Peninsula. [40] have implemented an adaptive moving window in the polynomial method developed in [45] and applied it to SMOS data over the Iberian Peninsula and Australia. The adaptive window in [40] had a radius of 9 SMOS pixels, while [44] used an adaptive window of different sizes and compared the results obtained with fixed window sizes from 4 to 7 SMAP pixels. The sizes considered in both studies allowed minimizing the regression residuals compared to using a larger spatial extent.

The algorithm presented in [46] was improved in [18,47]. DISPATCH (DISaggregation based on a Physical and Theoretical scale CHange) converts HR MODIS-derived SEE fields into HR SM fields by expanding a first order Taylor series of a SEE model around the LR SMOS SM. The HR SEE fields are derived using HR LST and NDVI data and the LR extreme temperatures, which are estimated from the LST-NDVI feature space [26,47]. Optical data are then linked to SM by using a self-calibrated SEE(SM) model [15]. DISPATCH also meets the meteorological forcing hypothesis, as it is self-calibrated at the SMOS pixel scale, where uniform atmospheric conditions are generally fulfilled, and can therefore be applied at large scales [15,48,49].

The current SEE(SM) model used in DISPATCH is linear; however, multiple studies have noted a strong nonlinear relationship between the microwave-derived SM and the optical-derived SEE [50-52]. The model provided in [51] has previously been implemented over the Australian landscape by $[46,53]$, by testing the DISPATCH approach at 10 and $4 \mathrm{~km}$ resolutions, respectively. They both used the nonlinear model in a second order disaggregation scheme of the SM data derived from the National Airborne Field Experiment, with satisfying results being reported. However, the impact of the nonlinear relationship between SEE and SM needs further investigation, in different surface conditions and at different resolutions, since this has not been addressed in previous studies. In particular, the nature of the model used within DISPATCH depends on the calibration strategy, and to date, there is no study analyzing the SEE(SM) calibration in both time and space.

Most of the thermal-based disaggregation techniques use a daily calibration of their parameters. In [36], a linkage model calibrated on a daily basis, combined with high resolution NDVI, surface albedo and LST, is applied to data acquired from the Special Sensor Microwave Imager (SSM/I) and Advanced Very High Resolution Radiometer (AVHRR) in order to derive high resolution SM estimates. In [37,45], a linking model is used to relate SMOS SM to MODIS NDVI and LST through regression coefficients, which are calibrated on a daily basis. The algorithm was also applied to SMOS and MSG (Meteosat Second generation) SEVIRI (Spinning Enhanced Visible and Infrared Imager) observations to derive $3 \mathrm{~km}$ resolution estimates over Spain and Southern France [38]. The same model is used by [39], with four different water indices formulations, in order to derive $500 \mathrm{~m}$ resolution soil moisture from SMOS and MODIS observations. A polynomial downscaling methodology is used in [54], with regression coefficients calibrated for every day over the observed scene, in order 
to derive HR SM estimates from AMSR-E (Advanced Microwave Scanning Radiometer on the Earth Observing System) and MSG SEVIRI observations. The UCLA method [32] uses a linear relationship to connect a soil wetness index with SM, index derived on a daily scale. In a similar manner, [33] use the VTCI (Vegetation Temperature Condition Index) instead of the soil water index in their downscaling methodology, which is derived on a daily basis by rescaling the LST of each pixel between two extreme LST values, per NDVI interval. The thermal inertia method is used by [25] to relate daily averaged SM estimates to diurnal changes in the soil temperature, calibrating their model on a monthly basis in order to reduce the impact of vegetation biomass on the estimates [17]. In this context, this study aims to improve the robustness of the SEE(SM) model used within the DISPATCH methodology and hence the accuracy of the disaggregated dataset. In this respect, this study implements the nonlinear SEE model developed by [51] in addition to the classic linear model (used in the current DISPATCH version) to disaggregate SMOS Level-3 SM down to $1 \mathrm{~km}$ resolution, over a range of different conditions. The impact of the calibration of each (linear and nonlinear) model is investigated. In practice, the linear and nonlinear models are calibrated on a daily and on a multi-date basis, and a comprehensive assessment is performed.

The approach is validated using in situ SM measurements for three different areas: over a mixed dry and irrigated area in Urgell, Catalonia, Spain (2011 and 2015), over an irrigated area in Algerri-Balaguer, Catalonia, Spain (2017-2018) and over a dry area in Morocco (2016-2017). The study sites along with all the data are presented in Section 2. In Section 3, the DISPATCH algorithm is briefly presented, along with the two SEE(SM) models. Section 4 offers a comparison between the disaggregated SM estimates.

\section{Data Description}

\subsection{Validation Sites and In Situ Data}

The study is based on data collected over three different sites: two regions (Urgell and the Algerri-Balaguer irrigation district) in Catalonia, northeast of Spain, and an arid area (hereby referred to as MOR3) located in the Guelmim-El Semara province in Morocco. Different sites were chosen to validate the downscaling approach: in irrigated areas, which are well suited for disaggregation (Urgell, Algerri-Balaguer), and in desert areas, which are not as well suited for disaggregation (MOR3). In particular, evaporation-based method consists of determining the wet and dry boundaries of the LST-NDVI feature space, which may or may not be present within the scene at the observation resolution. Therefore, limitations arise when fully dry and fully wet conditions are not met at the observation resolution [30]. DISPATCH, being an evaporation-based method, has been proven to work well for semi-arid areas (which, in our case, are represented by Urgell and Algerri Balaguer), where these boundaries can be observed. It is less adequate, for example, for homogeneous desert areas (MOR3 in our case), where the wet boundary can be overestimated when using $1 \mathrm{~km}$ resolution LST and NDVI data.

The two study areas located in the Urgell region and the Algerri-Balaguer irrigation district present a dry continental Mediterranean climate, with mild winters and dry and hot summers. A mean yearly precipitation of $400 \mathrm{~mm}, 60$ days of rain, and a mean yearly temperature of $16^{\circ} \mathrm{C}$ are registered over the area. Various irrigated crops (wheat, maize, alfalfa, apple and pear trees) and dryland crops (barley, olive trees, vineyards and almond trees) are present within the areas.

Two field experiments took place in the Urgell region, one conducted in 2011 and one in 2015. The experiments focused on a 20 by $20 \mathrm{~km}$ area to collect $0-5 \mathrm{~cm} \mathrm{SM}$ data using the gravimetric technique. The sampling used in this study spanned a total of seven days in 2011 (days of year (DOY) 98, 146, 165, 196, 228, 229 and 277) and five days in 2015 (DOY 143, 175, 210, 223 and 319). The sampling days were chosen roughly once per month for each field experiment, in an attempt to capture the seasonal variability also linked with the irrigation management within the area. 
The sampling covered a total of four areas in 2011, each of 3 by $3 \mathrm{~km}$. Two are situated in a dryland area and two in an irrigated area, with ten points per sampling area. In 2015, three of these areas were sampled, the two located in the irrigated area and just one in the dryland area. Three separate measurements per sampling point were performed, which means that a total of 120 measurements (for 2011) and 90 measurements (for 2015) were taken within the entire area each sampling day. As reported in [18], soil particle analysis at each sampling point, with a mean clay fraction of 0.24 and a mean sand fraction of 0.37 , was used to classify soil texture. The approach described in [55] was then used to convert the gravimetric measurements to volumetric values.

These in situ measurements serve here as a validation dataset for the downscaled SM products. Each of the 3 by $3 \mathrm{~km}$ sampling areas contain 9 pixels of $1 \mathrm{~km}$ resolution. Since the measurements performed are point measurements, they have been aggregated (simple average) to a $1 \mathrm{~km}$ resolution in order to be used in the validation process. A visual representation of the study area, along with the 1 by $1 \mathrm{~km}$ pixels is presented in Figure 1. For Urgell 2011, we have 36 pixels at $1 \mathrm{~km}$ resolution, each pixel being sampled at least 3 times in order to have spatial representativeness within the $1 \mathrm{~km}$ area. In the case of Urgell 2015, we have 27 pixels at $1 \mathrm{~km}$ resolution. The total number of data points, for the entire period, can be up to 252 (36 points/day multiplied by 7 sampling days) for 2011 and 135 ( 27 points/day multiplied by 5 sampling days). Please note that for the validation, we only select in situ points corresponding to available DISPATCH data over each $1 \mathrm{~km}$ pixel, which can lead to a total number of data points used in the analysis to be lower.

Two soil moisture stations were installed in the Algerri-Balaguer irrigation district in 2017. 5-TM sensors manufactured by Decagon Devices Inc. (now Meter Group) were installed for continuously measuring the soil moisture content at time intervals of 30 minutes. The sensors provide soil moisture measurements at nominal depths of $5 \mathrm{~cm}$ (two sensors), $25 \mathrm{~cm}$ (one sensor) and $50 \mathrm{~cm}$ (one sensor). In this study, only the data collected by the sensors located at $5 \mathrm{~cm}$ were used for validation purposes, covering the entire period between 17 March 2017 and 31 August 2018.

The reasoning behind choosing two irrigated sites is linked to the data availability. Urgell possesses a limited dataset acquired during field campaigns, whereas the Algerri-Balaguer irrigation district possesses continuous data records.

The MOR3 site is representative of a semi-arid climate, with an average temperature of $12{ }^{\circ} \mathrm{C}$ in winter and $30^{\circ} \mathrm{C}$ in summer. The mean precipitation recorded is of $217 \mathrm{~mm}$. The site is equipped with two Decagon EC-5 surface sensors at a $5 \mathrm{~cm}$ depth and one sensor at a $15 \mathrm{~cm}$ depth. The sand percentage is estimated to be between $39 \%$ to $57 \%$ and clay between $22 \%$ to $24 \%$ according to ecoclimap and soilgrids, respectively. The dataset used for validation concerns the $5 \mathrm{~cm}$ depth sensors only and covers the entire period between 2 April 2016 and 1 March 2017.

Table 1 offers a summary concerning information related to the study areas, number of datasets used, in situ acquisition days/periods, and satellite products used. Note that the number of datasets used refers to the total number of samples used for the entire time period in the $1 \mathrm{~km}$ validation, detailed in Section 4.2.

Table 1. Summary of in situ areas characteristics, alongside the acquisition days/periods, number of datasets used and corresponding satellite data used.

\begin{tabular}{|c|c|c|c|}
\hline & Urgell & Algerri Balaguer & MOR3 \\
\hline Climate & Dry continental Mediterranean & Dry continental Mediterranean & Semi-arid \\
\hline Yearly precipitation (mm) & 400 & 400 & 217 \\
\hline Yearly temperature & $16^{\circ} \mathrm{C}$ & $16^{\circ} \mathrm{C}$ & $12{ }^{\circ} \mathrm{C}$ (winter); $30^{\circ} \mathrm{C}$ (summer) \\
\hline Land use & Irrigated and dryland crops & Irrigated and dryland crops & Desert \\
\hline Acquisition dates & $\begin{array}{c}2011 \text { DOY } 98,146,165,196,228,229 \\
2015 \text { DOY } 143,175,210,223,319\end{array}$ & March 2017-August 2018 & April 2016-March 2017 \\
\hline Number of datasets used & $\begin{array}{l}231 \text { (in 2011) } \\
102(\text { in 2015) }\end{array}$ & 188 & 256 \\
\hline SMOS products & CLF31A/D L3 SM & CLF31A/D L3 SM & CLF31A/D L3 SM \\
\hline MODIS products & $\begin{array}{l}\text { MOD11A1/MYD11A1 LST } \\
\text { MOD13A2 NDVI }\end{array}$ & $\begin{array}{l}\text { MOD11A1/MYD11A1 LST } \\
\text { MOD13A2 NDVI }\end{array}$ & $\begin{array}{l}\text { MOD11A1/MYD11A1 LST } \\
\text { MOD13A2 NDVI }\end{array}$ \\
\hline
\end{tabular}




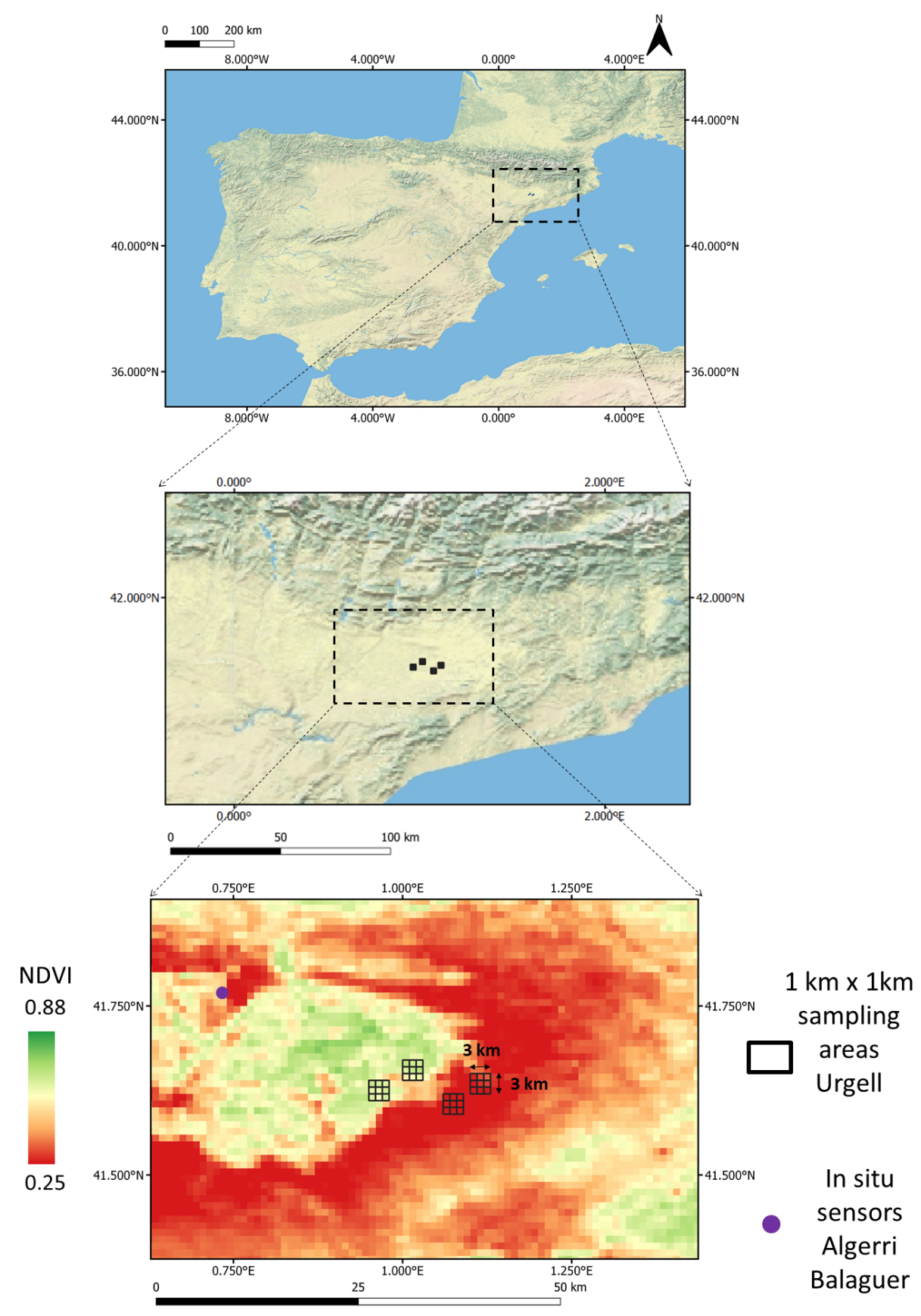

Figure 1. The Urgell and Algerri-Balaguer study areas.

\subsection{Remote Sensing Data}

The SMOS Level-3 1-day global SM product (MIR CLF31A/D), version 3 (in 300 reprocessing mode RE04) product is used. SMOS data are extracted over an 80 by $120 \mathrm{~km}$ area over Spain and over a 120 by $80 \mathrm{~km}$ area over Morocco. SMOS data are then re-sampled at a grid spacing of $40 \mathrm{~km}$.

The sampling grid of the original SMOS global product $(\sim 25 \mathrm{~km})$ is finer than the SMOS nominal average resolution $(\sim 40 \mathrm{~km})$. In order to take advantage of this oversampling inherent to SMOS products, the re-sampling methodology described in $[15,56]$ was used. It consists of obtaining re-sampled SMOS data, which overlap four times over the study area, by sliding a $40 \mathrm{~km}$ resolution window over the original grid, such that the pixel centers are coincident. The final downscaled SM product is generated on the intersection of these four SMOS grids. 
The MODIS version-6 LST products onboard Terra (MOD11A1, [57]) and Aqua (MYD11A1, [58]) and NDVI product onboard Terra (MOD13A2, [59]) were downloaded using the NASA Land Processes Distributed Active Archive Center (LP DAAC). Both the LST and NDVI products are re-sampled on a $1 \mathrm{~km}$ grid using the bilinear re-sampling method.

Elevation data extracted from the GTOPO30 digital elevation model (DEM) are also required. Figure 1 shows the Urgell and Algerri-Balaguer study areas on which the downscaling algorithm is applied. A visual assessment of the $1 \mathrm{~km}$ resolution Terra 16-day NDVI on doy 161 in 2011 is also represented, where we can clearly distinguish the irrigated and dryland areas. Figure 2 shows the MOR3 study area. The $1 \mathrm{~km}$ resolution Terra 16-day NDVI on doy 241 in 2016 is also shown.

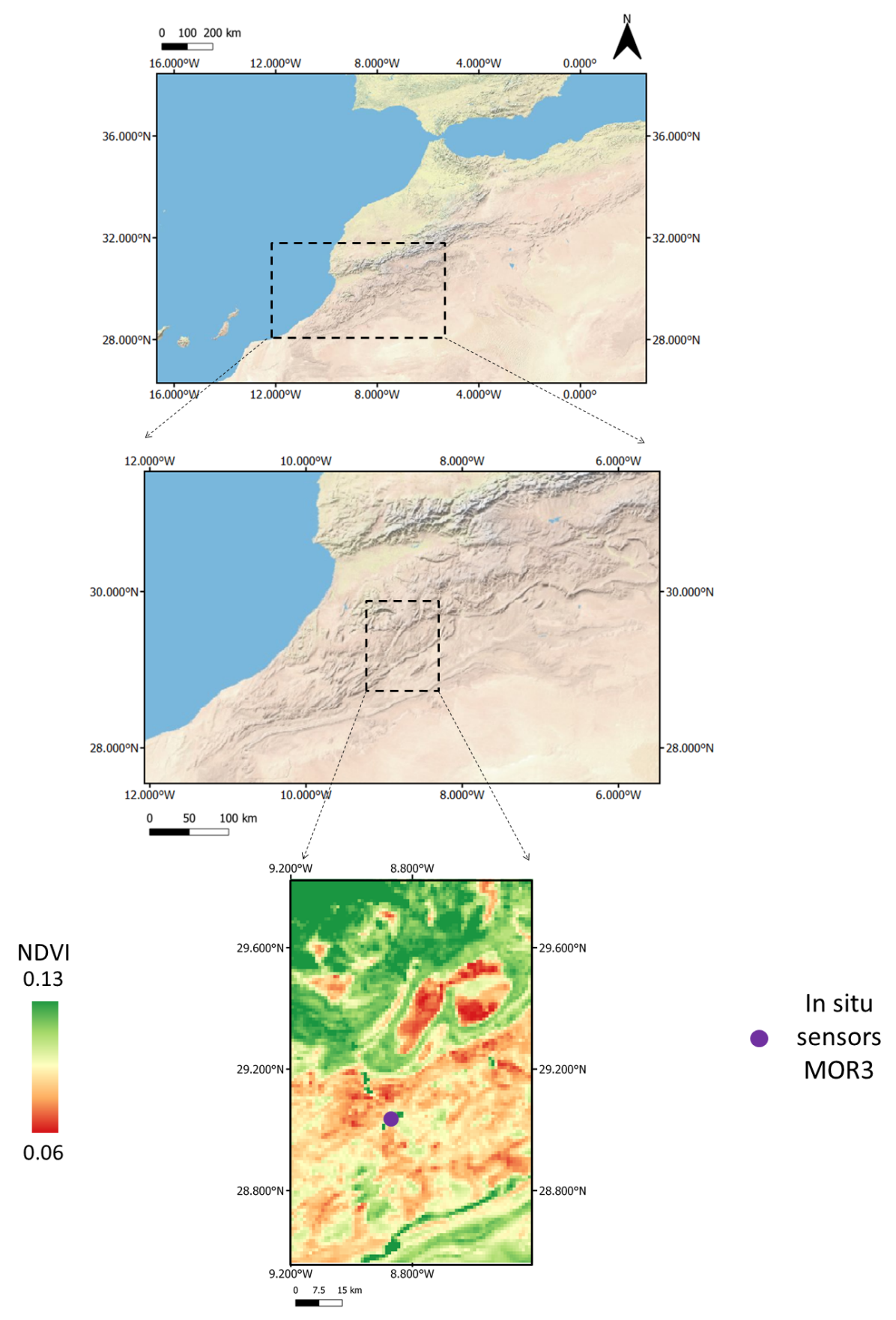

Figure 2. The MOR3 study area. 


\section{Methodology}

\subsection{DISPATCH}

The operational version of the DISPATCH algorithm [18] is fully described in [15]. Only the essential aspects are reminded herein. Briefly, DISPATCH converts HR MODIS-derived SEE fields into HR SM fields by expanding a first order Taylor series of a SEE model around the LR SMOS SM value. Different combinations of SMOS SM (ascending 6 a.m. and descending 6 p.m.) and MODIS (Terra overpass 10:30 a.m. and Aqua 1:30 p.m. from one day before until one day after the SMOS overpass) data are used to generate an input ensemble. The DISPATCH product is the average at $1 \mathrm{~km}$ resolution of the disaggregated output ensemble [15,48].

The downscaling relationship is written as:

$$
S M_{H R}=S M_{L R}+\frac{d S M_{m o d}}{d S E E}\left(S E E_{L R}\right) *\left(S E E_{H R}-S E E_{L R}\right)
$$

With $S M_{H R}$ being the $1 \mathrm{~km}$ disaggregated $S M, S M_{L R}$ the SMOS observation, $\frac{d S M_{\text {mod }}}{d S E E}\left(S E E_{L R}\right)$ the partial derivative of SM with respect to SEE, evaluated at the SMOS scale, $S E E_{H R}$ the MODIS-derived $S E E$, and $S E E_{L R}$ its average within the SMOS pixel.

DISPATCH thus relies on two different SEE models: a temperature-based model, used to derive $S E E_{H R}$ from MODIS data, and an SM-based model (partial derivative of SM with respect to SEE in Equation (1)), used to link the temperature-based SEE to SM. The temperature-based SEE is derived as a function of the retrieved soil temperature and the soil temperature that would occur in completely dry and completely wet conditions. More details regarding the temperature-based model can be found in $[15,18]$.

\subsection{SM-Based SEE}

\subsubsection{Linear Model}

The current version of DISPATCH links the SM and the SEE using a semi-empirical linear model $[60,61]$ :

$$
S E E_{H R}=\frac{S M_{H R}}{S M_{p}}
$$

With $S M_{p}$ being a parameter estimated at LR as:

$$
S M_{p}=\frac{S M_{L R}}{S E E_{L R}}
$$

In this study, the calibration of $S M_{p}$ is done both from daily $S M_{L R}$ and $S E E_{L R}$ observations, as well as on a multi-date basis, as the average of the daily $S M_{p}$ values estimated throughout the corresponding study period.

The performance of this linear model has been successfully assessed within DISPATCH in $[15,18,48]$. The linearity assumption was proven to be adequate at the kilometric scale using the daily calibration approach. Moreover, the reasons behind using a linear model as in Equation (3) are twofold. One reason is the potential robustness it could provide over a nonlinear model with an erroneous behavior [52]. The second reason is that the daily calibrated $S M_{p}$ parameter could contribute to the description of the real behavior of SEE [18].

However, SEE is known to actually have a strongly nonlinear behavior over the full SM range [52,62-64], which represents a fundamental limitation of the SEE model in Equation (2). In fact, the derivative of SEE with respect to SM is influenced by the SM range, and generally decreases with an increase of SM [51]. 


\subsubsection{Nonlinear Model}

Previous versions of the DISPATCH algorithm $[46,47,53]$ have tested a range of nonlinear models of SEE: [50,51,62]. Regarding nonlinear SEE representations, the model presented in [51] presents a particular interest compared to the linear approximation, and the reason is twofold: i) it lowers the derivative $\left(\frac{d S M \text { mod }}{d S E E}\right)$ in Equation (1) in the lower ranges of the $S M_{L R}$ and ii) it increases $\frac{d S M \text { mod }}{d S E E}$ in the higher ranges of the $S M_{L R}$. On the one hand, it is important not to have large values of the derivative at $S M_{L R} \sim 0$. A large derivative would maximize the variability of the disaggregated SM in situations where the variability of SM should be very small (SM close to zero on average). On the other hand, a derivative increasing continuously with $S M_{L R}$ is desired to counter the saturation effect of SEE in the higher SM ranges [51].

Note that the models presented in [50,62] do not allow a low derivative in the low ranges of the $S M_{L R}$, as the simulated SEE slowly increases with SM in the lower ranges of SM. This implies that a very large derivative is obtained, leading to an unstable behavior of the disaggregation algorithm for low $S M_{L R}$ values.

For the above-mentioned reasons, the exponential form of [51] (hereby mentioned as K03) is chosen as a nonlinear SEE model:

$$
S E E_{\text {sim }}=1-\exp \left(-\frac{S M}{S M_{c}}\right)
$$

where $S M_{c}$ is a semi-empirical parameter. In our case, $S M_{c}$ is supposed to be constant in space (within each LR pixel). Two calibrations at $L R$ of the $S M_{c}$ parameter are performed for each SMOS pixel: on a daily and on a multi-date basis, from SMOS and MODIS data.

For the daily calibration, Equation (4) is inverted and applied at LR:

$$
S M_{c}=-\frac{S M}{\ln \left(1-S E E_{\text {sim }}\right)}
$$

For the multi-date calibration, the $S M_{c}$ parameter is retrieved by minimizing the cost function:

$$
\left\|\sum_{i=1}^{N}\left(S E E_{s i m, i}-S E E_{o b s, i}\right)\right\|^{2}
$$

where $\mathrm{N}$ is the number of SMOS/MODIS dates, and the observed SEE is the $S E E_{L R}$ (spatial linear average of $\left.S E E_{H R}\right)$.

\section{Results and Discussion}

In this section, the performance of the linear and nonlinear models with the daily and multi-date calibrations is assessed in terms of disaggregated SM values. Two types of validations are performed: a spatial validation on a daily time scale and a spatio-temporal validation. More specifically, the disaggregated SMOS SM using both the linear and nonlinear models, in both calibration modes, are compared against in situ measurements, for each study area separately. The reasoning behind doing two types of validation is that on the one hand, the spatial validation is the type of validation to perform in order to evaluate the disaggregation methodology. On the other hand, this can only be done for Urgell 2011 and 2015. Since the measurements for Urgell are short in time, we performed a temporal validation by adding Algerri Balaguer and MOR3, the latter site being added in order to test DISPATCH in an area that is not suitable for disaggregation (i.e., arid area). 


\subsection{Spatial Validation}

A spatial validation was performed at the daily time scale for Urgell 2011 and Urgell 2015, to evaluate the spatial representation of the DISPATCH SM at the sub-SMOS-pixel scale. As mentioned in [18], this type of validation is particularly useful for disaggregation methodologies, as it allows to separate the spatial and temporal trends provided by SMOS and by DISPATCH.

Table 2 shows the range (considering all days) of the correlation coefficient, slope of linear regression, bias and uRMSE obtained for Urgell 2011, taking into account both models and calibrations. For each range interval, the mean value (simple average for all days) of correlation, slope, bias and uRMSE. Table 3 shows the same statistics obtained for Urgell 2015.

Table 2. Range of correlation coefficient, slope of the linear regression, bias $\left(\mathrm{m}^{3} / \mathrm{m}^{3}\right), \mathrm{uRMSE}\left(\mathrm{m}^{3} / \mathrm{m}^{3}\right)$ between SMOS SM/DISPATCH SM and in situ data. DISPATCH is tested with both linear and nonlinear modes, and with both daily and yearly calibrations. Note that for each range interval, the mean value (simple average for all days) of correlation, slope, bias and uRMSE is also mentioned in bold.

\begin{tabular}{|c|c|c|c|c|c|}
\hline & \multirow{2}{*}{ SMOS } & \multicolumn{2}{|c|}{ Daily Calibration } & \multicolumn{2}{|c|}{ Yearly Calibration } \\
\hline & & Linear & Nonlinear & Linear & Nonlinear \\
\hline $\mathrm{R}$ & {$[-0.65 ;-0.24 ; 0.33]$} & {$[-0.21 ; 0.12 ; 0.44]$} & {$[-0.26 ; \mathbf{0 . 1 1} ; 0.49]$} & {$[-0.64 ;-0.24 ; 0.33]$} & {$[-0.23 ; 0.17 ; 0.57]$} \\
\hline Bias & {$[-0.226 ;-\mathbf{0 . 0 9 7} ; 0.009]$} & {$[-0.220 ;-\mathbf{0 . 1 0 0} ;-0.007]$} & {$[-0.222 ;-\mathbf{0 . 1 0 1} ;-0.011]$} & {$[-0.226 ;-\mathbf{0 . 0 9 8} ; 0.009]$} & {$[-0.139 ;-0.095 ;-0.037]$} \\
\hline uRMSE & {$[0.101 ; \mathbf{0 . 0 6 9 ; 0 . 0 0 4 ]}$} & {$[0.085 ; \mathbf{0 . 0 6 6} ; 0.006]$} & {$[0.093 ; \mathbf{0 . 0 6 9} ; 0.008]$} & {$[0.098 ; \mathbf{0 . 0 7 0} ; 0.004]$} & {$[0.092 ; 0.067 ; 0.016]$} \\
\hline
\end{tabular}

Table 3. Same as Table 2, but for Urgell 2015.

\begin{tabular}{|c|c|c|c|c|c|}
\hline & \multirow{2}{*}{ SMOS } & \multicolumn{2}{|c|}{ Daily Calibration } & \multicolumn{2}{|c|}{ Yearly Calibration } \\
\hline & & Linear & Nonlinear & Linear & Nonlinear \\
\hline $\mathrm{R}$ & {$[-0.31 ; 0.09 ; 0.43]$} & {$[0.40 ; 0.59 ; 0.75]$} & {$[-0.31 ; 0.09 ; 0.43]$} & {$[-0.31 ; 0.09 ; 0.43]$} & {$[0.57 ; 0.66 ; 0.81]$} \\
\hline Bias & {$[-0.160 ;-\mathbf{0 . 0 7 0} ;-0.014]$} & {$[-0.110 ;-0.027 ; 0.002]$} & {$[-0.160 ;-0.070 ;-0.014]$} & {$[-0.16 ;-0.070 ;-0.014]$} & {$[-0.082 ;-0.023 ; 0.003]$} \\
\hline uRMSE & {$[0.110 ; \mathbf{0 . 0 7 7} ; 0.061]$} & {$[0.097 ; \mathbf{0 . 0 6 8} ; 0.053]$} & {$[0.110 ; \mathbf{0 . 0 7 7} ; 0.061]$} & {$[0.110 ; \mathbf{0 . 0 7 7} ; 0.061]$} & {$[0.081 ; 0.060 ; 0.047]$} \\
\hline
\end{tabular}

\subsubsection{Daily Calibration}

When doing a spatial validation in the daily calibration mode, the results obtained with the nonlinear model are slightly better than the one obtained with the linear model in the case of Urgell 2011, whereas for Urgell 2015, the linear model performs better.

When comparing at the daily time scale, the linear model gives better correlation values than the nonlinear model in the case of Urgell 2015, with an average value of 0.59 as opposed to 0.09 . In the case of Urgell 2011, the results are comparable: a mean of 0.12 (linear model) and 0.11 (nonlinear model), with ranges of $[-0.21 ; 0.44]$ and $[-0.26 ; 0.49]$, respectively.

In the case of the slope of linear regression, the results are also similiar over Urgell 2011: a mean of 0.05 (linear model) and 0.06 (nonlinear model). Nevertheless, the range of the nonlinear model is slightly better than the range of the linear model: $[-0.05 ; 0.25]$ as opposed to $[-0.05 ; 0.14]$. In the case of Urgell 2015, the linear model is superior to the nonlinear model, with a mean slope of 0.47 as opposed to -0.04 .

Low values of bias have been obtained using both models. In the case of Urgell 2011, the values of the mean bias is $\sim-0.1 \mathrm{~m}^{3} / \mathrm{m}^{3}$ for both models, while for Urgell 2015 , a lower mean bias is obtained with the linear model: $-0.027 \mathrm{~m}^{3} / \mathrm{m}^{3}$ as opposed to $-0.070 \mathrm{~m}^{3} / \mathrm{m}^{3}$.

Low values of uRMSE have been registered, which in general are slightly lower when using the linear model for both sites: a mean value of 0.066 for Urgell 2011 and 0.068 for Urgell 2015.

\subsubsection{Yearly Calibration}

When looking at the yearly calibration mode, the nonlinear model further improves the correlation coefficient: a mean value of 0.17 is obtained for Urgell 2011 and 0.66 for Urgell 2015. 
The bias remains roughly the same, with a mean value $\sim-0.010 \mathrm{~m}^{3} / \mathrm{m}^{3}$ for Urgell 2011 and $-0.023 \mathrm{~m}^{3} / \mathrm{m}^{3}$ for Urgell 2015, comparable with the values obtained with the linear model with a daily calibration.

However, when comparing both models in all calibration modes, the nonlinear model in the yearly calibration mode systematically improves the results. In the case of Urgell 2011, the range of correlation coefficients is improved from [ $-0.26 ; 0.49$ ] (nonlinear model, daily calibration) to [ $-0.23 ; 0.57]$. In the same manner, the higher end of the range of the slope of linear regression is also improved from 0.25 (nonlinear model, daily calibration) to 0.42. In the case of Urgell 2015, the range of the correlation coefficient improves from [0.40; 0.75] (linear model, daily calibration) to [0.57; 0.81], while the lower limit of the range of the slope of linear regression increases from 0.18 (linear model, daily calibration) to 0.36 .

In general, better correlations have been found for both the linear and nonlinear models on sampling dates with larger spatial variability in the SM measurements. One such example is presented in Figure 3, which shows a visual representation of the SMOS and DISPATCH SM (in linear mode with daily calibration-current operational version of the algorithm, and in the nonlinear mode with yearly calibration - the combination that yields the best results over the area). Results are shown for DOY 196 (year 2011) and DOY 223 (year 2015). One can observe that compared to the SMOS SM, both DISPATCH products better capture the spatial variability within the area, distinguishing between the dryland and the irrigated area. Moreover, the variability is higher in the case of the nonlinear model with a yearly calibration.

SMOS

(a)

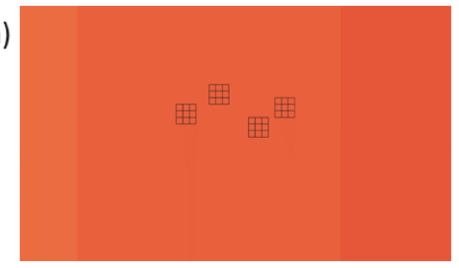

(b)

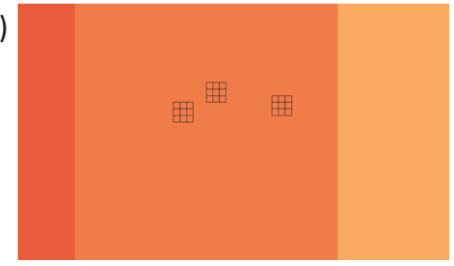

DISPATCH Linear, daily
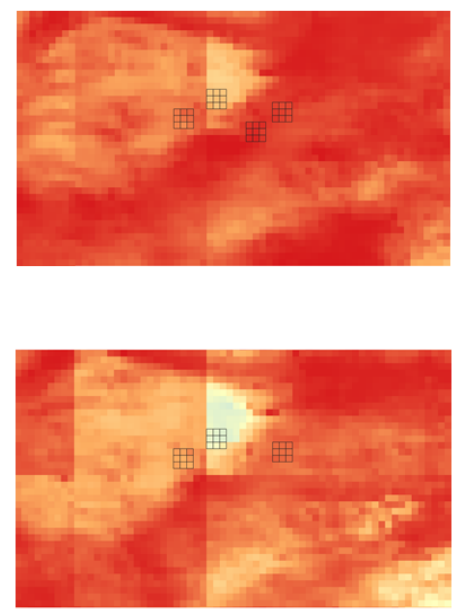

DISPATCH Nonlinear, yearly
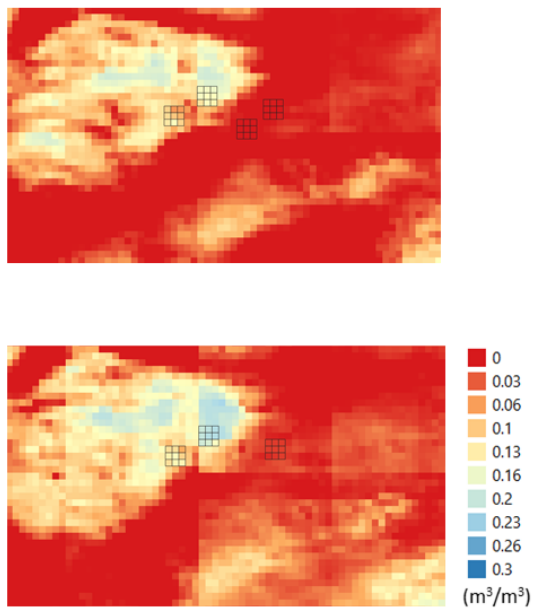

Figure 3. The SMOS and DISPATCH SM on DOY 196 (year 2011)—(a) and DOY 223 (year 2015)—(b). DISPATCH SM is obtained using the linear SEE(SM) model with a daily calibration and the nonlinear SEE(SM) model with a yearly calibration. The $1 \times 1 \mathrm{~km}$ pixels within the sampling areas are also shown (four 3 by $3 \mathrm{~km}$ sites for 2011 and three for 2015).

In the same manner as for Figure 3, Figure 4 shows the SMOS SM and the DISPATCH output with respect to in situ measurements for DOY 196 (year 2011), while Figure 5 shows the SMOS SM and the DISPATCH output with respect to in situ measurements for DOY 223 (year 2015). The error bars present in the plots represent the standard deviation. It is reminded that the in situ dataset corresponding to Urgell (collected by gravimetric measurements) was aggregated at a $1 \mathrm{~km}$ scale by simple linear averaging, for the sampling days. The DISPATCH output presented corresponds to the linear SEE(SM) model with the daily calibration mode, and to the nonlinear SEE(SM) model with the yearly calibration mode. 

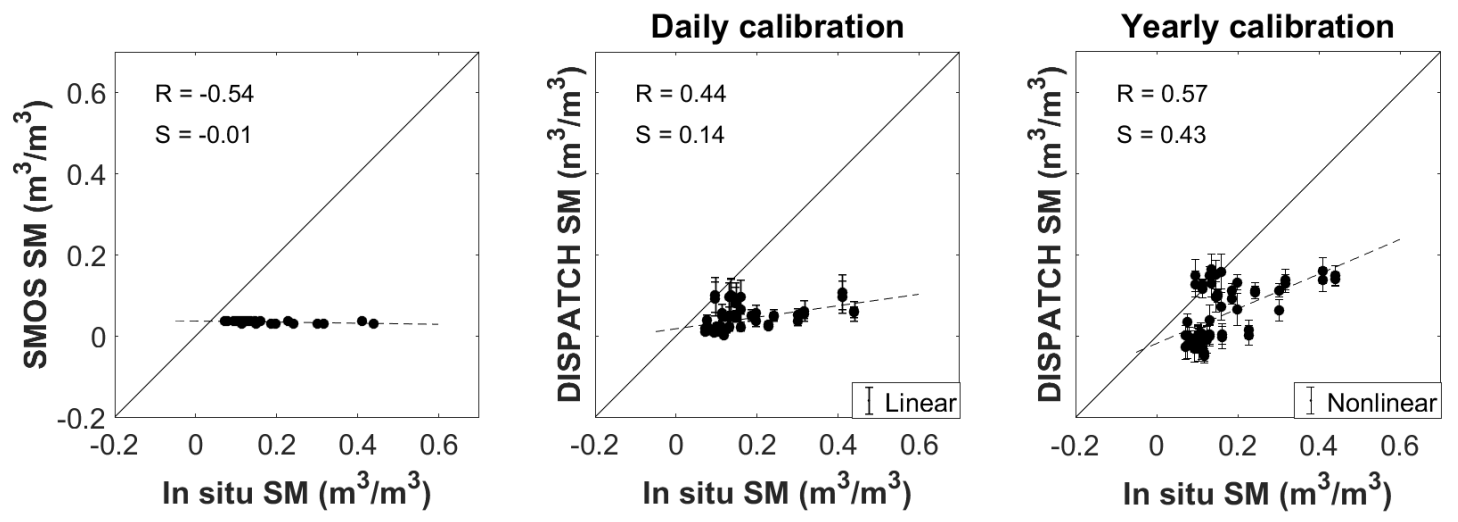

Figure 4. The SMOS and DISPATCH SM are plotted against $1 \mathrm{~km}$ aggregated Urgell in situ measurements for DOY 196 (year 2011). The correlation coefficient (R) and slope of linear regression (S) are also shown in each case.
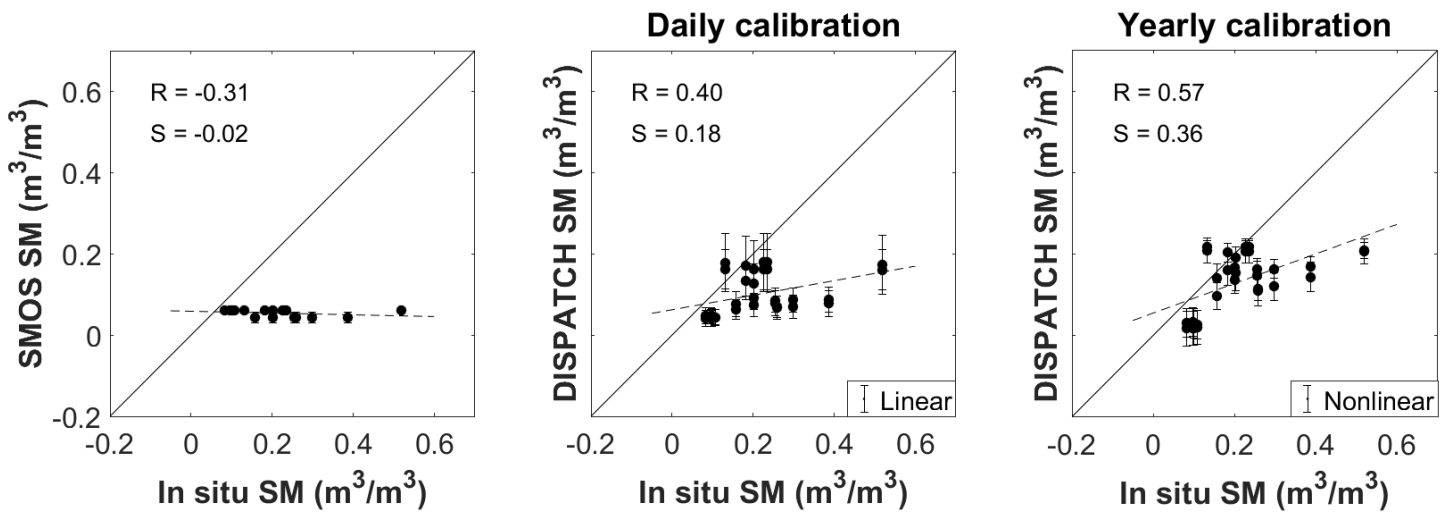

Figure 5. The SMOS and DISPATCH SM are plotted against $1 \mathrm{~km}$ aggregated Urgell in situ measurements for DOY 223 (year 2015). The correlation coefficient (R) and slope of linear regression (S) are also shown in each case.

The correlation coefficient is improved from -0.54 (SMOS) to 0.44 (linear model, daily calibration) and to 0.57 (nonlinear model, yearly calibration) for DOY 196 (year 2011), while the slope of linear regression also increases from -0.01 to 0.14 and 0.43 , respectively. In the case of DOY 223 (year 2015), the correlation coefficient increases from -0.31 to 0.40 and 0.57 , respectively, while the slope of linear regression is improved from -0.02 to 0.18 and to 0.36 , respectively.

Even though better correlations have been found on sampling dates with larger spatial variability in the SM measurements, however, if the spatial variability is relatively large (due to the irrigated area), the linear model is less effective than the nonlinear model, as the nonlinearity effects of the SEE(SM) relationship become more apparent [65]. In terms of the slope of linear regression, [66] have shown it is a good indicator of the efficiency of the downscaling technique. In our case, the slope of the linear regression is systematically increased by the nonlinear model with the multi-date calibration, indicating it disaggregates the SMOS SM in a more effective way than the other model-calibration options. Another aspect to be taken into account is that the uncertainty in the downscaled SM when using a daily calibration might be associated with uncertainty in the daily retrieved parameters. This coupled with the nonlinear model being able to better capture the nonlinearity effects inherent to the SEE might explain the better performance of the nonlinear model in the daily calibration mode over Urgell 2011. In the case of Urgell 2015, the validation is performed over areas containing more pixels in the irrigated zone, and there seems to be compensation effects in the case of the linear model with the daily calibration, making it better suited than the nonlinear model with a daily calibration. 


\subsection{Spatio-Temporal Validation}

As mentioned at the beginning of Section 4, although the spatial validation is best suited to analyze the performance of the disaggregation methodology, the measurements for Urgell only span several days. Hence, we perform a temporal validation by adding two new sites: Algerri Balaguer and MOR3. We also include Urgell 2011 and 2015 in the temporal validation. Statistical results in terms of correlation coefficient, slope of linear regression, bias and unbiased root mean square error (uRMSE) between satellite and in situ SM are reported in Tables 4-7 for Urgell 2011, Urgell 2015, Algerri Balaguer and MOR3, respectively. In each case, DISPATCH is tested with the linear and nonlinear modes, with both daily and multi-date calibrations. The sample size used in each analysis is also mentioned.

Table 4. Correlation coefficient, slope of the linear regression, bias, unbiased RMSE (uRMSE) between SMOS SM/DISPATCH SM and in situ data are reported, alongside the sample size used in the analysis. DISPATCH is tested with the linear and the nonlinear modes, with the daily and multi-date calibration.

\begin{tabular}{cccccc}
\hline & \multirow{2}{*}{ SMOS } & \multicolumn{2}{c}{ Daily Calibration } & \multicolumn{2}{c}{ Yearly Calibration } \\
\cline { 3 - 6 } & & Linear & Nonlinear & Linear & Nonlinear \\
\hline Sample size & 10 & 231 & 231 & 231 & 231 \\
$\mathrm{R}$ & -0.29 & 0.27 & 0.31 & 0.02 & 0.54 \\
$\mathrm{~S}$ & -0.04 & 0.10 & 0.13 & 0.00 & 0.36 \\
Bias $\left(\mathrm{m}^{3} / \mathrm{m}^{3}\right)$ & -0.102 & -0.101 & -0.101 & -0.101 & -0.099 \\
uRMSE $\left(\mathrm{m}^{3} / \mathrm{m}^{3}\right)$ & 0.102 & 0.094 & 0.093 & 0.100 & 0.079 \\
\hline
\end{tabular}

Table 5. Same as Table 4, but for Urgell 2015.

\begin{tabular}{cccccc}
\hline & \multirow{2}{*}{ SMOS } & \multicolumn{2}{c}{ Daily Calibration } & \multicolumn{2}{c}{ Yearly Calibration } \\
\cline { 2 - 6 } & & Linear & Nonlinear & Linear & Nonlinear \\
\hline Sample size & 13 & 102 & 102 & 102 & 102 \\
$\mathrm{R}$ & 0.08 & 0.44 & 0.08 & 0.08 & 0.57 \\
$\mathrm{~S}$ & 0.05 & 0.44 & 0.05 & 0.05 & 0.47 \\
Bias $\left(\mathrm{m}^{3} / \mathrm{m}^{3}\right)$ & -0.079 & -0.041 & -0.079 & -0.079 & -0.031 \\
uRMSE $\left(\mathrm{m}^{3} / \mathrm{m}^{3}\right)$ & 0.096 & 0.092 & 0.096 & 0.096 & 0.073 \\
\hline
\end{tabular}

Table 6. Same as Table 4, but for Algerri-Balaguer.

\begin{tabular}{cccccc}
\hline & \multirow{2}{*}{ SMOS } & \multicolumn{2}{c}{ Daily Calibration } & \multicolumn{2}{c}{ Yearly Calibration } \\
\cline { 2 - 6 } & & Linear & Nonlinear & Linear & Nonlinear \\
\hline Sample size & 188 & 188 & 188 & 188 & 188 \\
R & -0.20 & 0.18 & -0.08 & -0.08 & 0.47 \\
S & -0.49 & 0.44 & -0.14 & -0.14 & 1.16 \\
Bias $\left(\mathrm{m}^{3} / \mathrm{m}^{3}\right)$ & -0.138 & -0.114 & -0.153 & -0.153 & -0.063 \\
uRMSE $\left(\mathrm{m}^{3} / \mathrm{m}^{3}\right)$ & 0.066 & 0.061 & 0.056 & 0.056 & 0.054 \\
\hline
\end{tabular}

Table 7. Same as Table 4, but for MOR3.

\begin{tabular}{cccccc}
\hline & \multirow{2}{*}{ SMOS } & \multicolumn{2}{c}{ Daily Calibration } & \multicolumn{2}{c}{ Yearly Calibration } \\
\cline { 3 - 6 } & & Linear & Nonlinear & Linear & Nonlinear \\
\hline Sample size & 256 & 256 & 256 & 256 & 256 \\
$\mathrm{R}$ & 0.24 & 0.32 & 0.30 & 0.24 & 0.34 \\
$\mathrm{~S}$ & 0.52 & 0.58 & 0.61 & 0.52 & 0.75 \\
Bias $\left(\mathrm{m}^{3} / \mathrm{m}^{3}\right)$ & 0.005 & -0.001 & -0.002 & 0.005 & -0.004 \\
$\mathrm{uRMSE}\left(\mathrm{m}^{3} / \mathrm{m}^{3}\right)$ & 0.032 & 0.028 & 0.031 & 0.032 & 0.032 \\
\hline
\end{tabular}

Figures 6-9 show the SMOS SM and the DISPATCH output with respect to in situ measurements for Urgell (2011 and 2015 time periods), Algerri-Balaguer and MOR3. In the same manner as for the spatial validation, the in situ dataset corresponding to Urgell (collected by gravimetric measurements) was aggregated at a $1 \mathrm{~km}$ scale by simple linear averaging, for the sampling days. The DISPATCH output presented corresponds to the linear SEE(SM) model with the daily calibration mode, and to the nonlinear SEE(SM) model with the yearly calibration mode. 

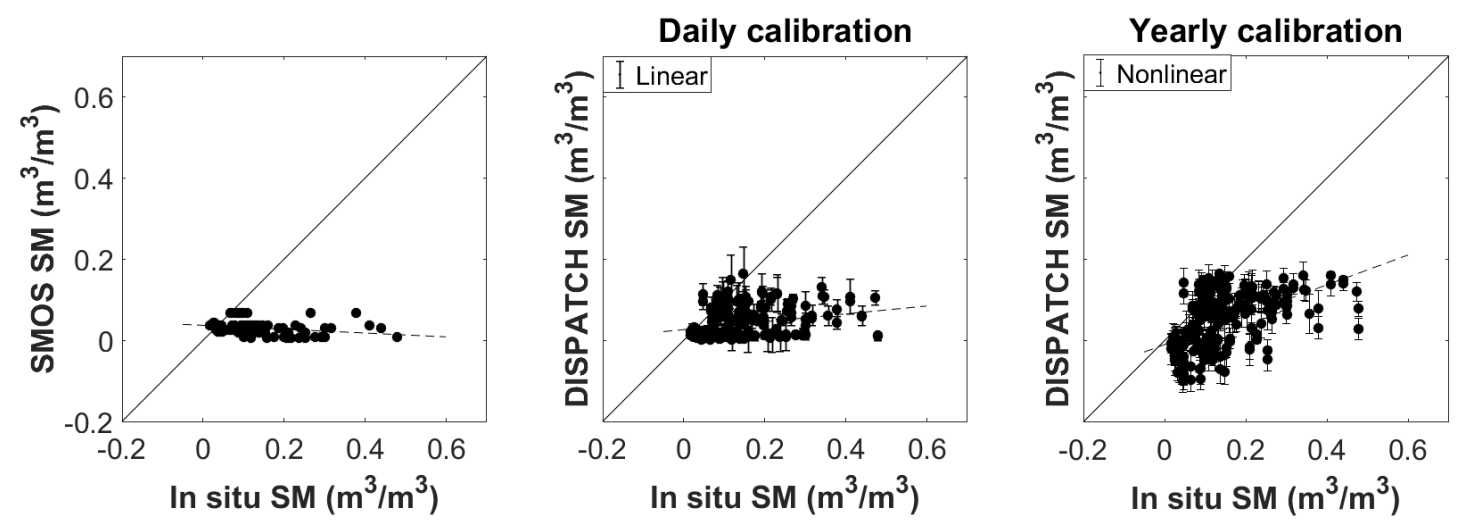

Figure 6. The SMOS and DISPATCH SM are plotted against $1 \mathrm{~km}$ aggregated Urgell in situ measurements (for 2011).
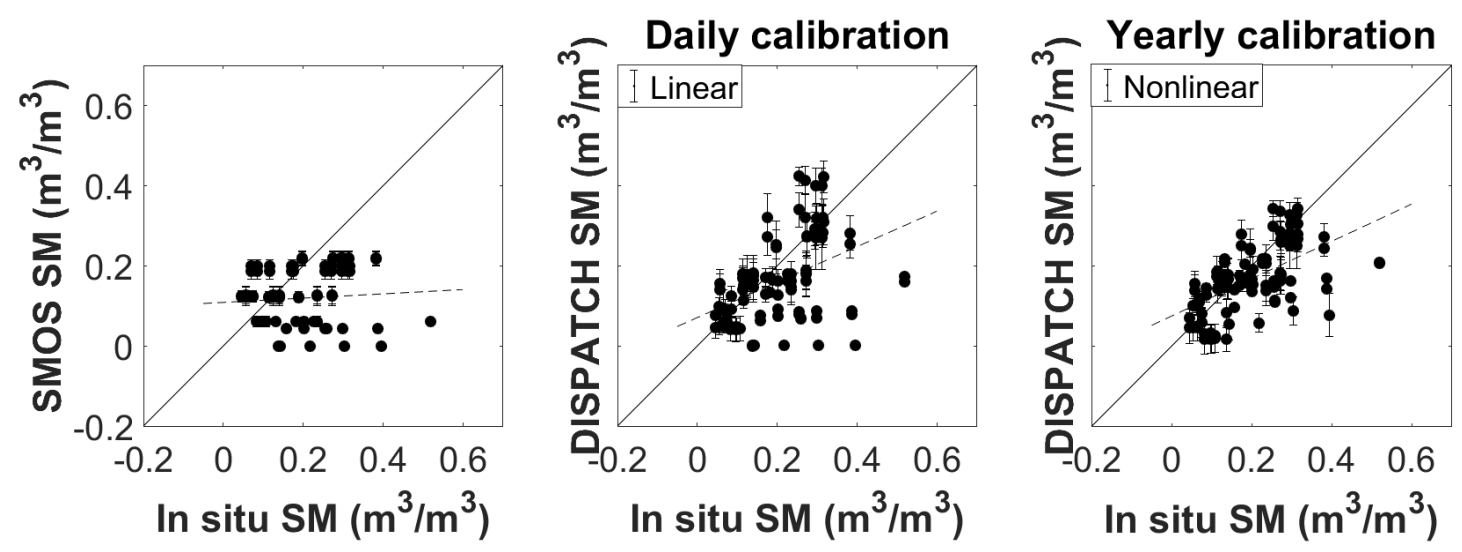

Figure 7. The SMOS and DISPATCH SM are plotted against $1 \mathrm{~km}$ aggregated Urgell in situ measurements (for 2015).
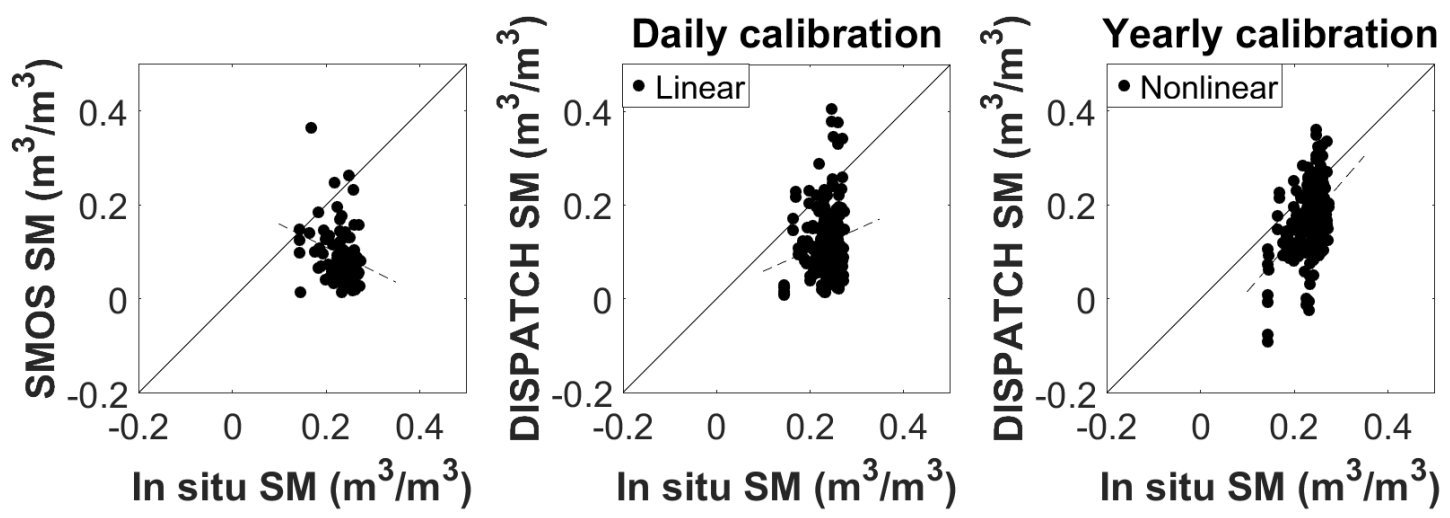

Figure 8. The SMOS and DISPATCH SM are plotted against measurements collected from sensors over the Algerri-Balaguer region. 

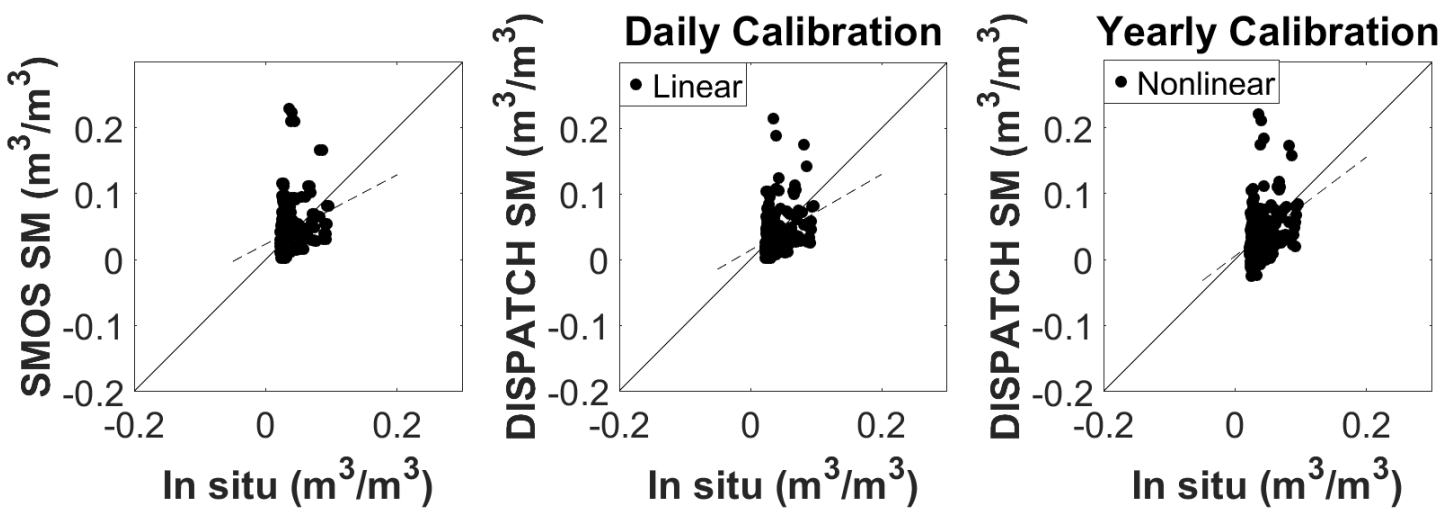

Figure 9. The SMOS and DISPATCH SM are plotted against measurements collected from sensors over the MOR3 region.

First, results are presented per calibration mode, and then a discussion will be performed.

\subsubsection{Daily Calibration Mode}

When analyzing the LR and HR SM values over the areas, DISPATCH improves the fine-scale precision compared to the non-disaggregation case, regardless of the model and calibration. When comparing the linear and the nonlinear models in the daily calibration mode, the nonlinear model performs poorly in the case of Urgell 2015 (corroborating the results obtained for the spatial validation) and Algerri Balaguer.

For Urgell 2011, correlation coefficients equal to 0.27 and to 0.31 (when using the linear and nonlinear modes, respectively) are obtained, as opposed to -0.29 when comparing SMOS SM with in situ data. In a similar manner, for Urgell 2015, the correlation increases from 0.08 (SMOS) to 0.44 (DISPATCH linear mode). In the case of the Algerri-Balaguer site, the correlation coefficient increases from -0.20 (SMOS) to 0.18 (DISPATCH linear mode) and -0.08 (DISPATCH nonlinear mode).

The low correlation values obtained have prompted an analysis (not shown) of the Radio Frequency Interference (RFI) in the SMOS products. Results have shown strong values of RFI in the area of Algerri-Balaguer, which can have an impact on the results. Despite the fact that L3 SMOS SM are RFI filtered [67], our analysis has shown that RFI effects might remain in the filtered products that we use in our analysis as input to DISPATCH. As for the MOR3 site, the correlation increases from 0.24 (SMOS) to 0.32 and to 0.30 (DISPATCH linear and nonlinear modes, respectively).

The slope of the linear regression is also improved from -0.04 (SMOS) to 0.10 (linear mode) and to 0.13 (nonlinear mode) for the Urgell region, 2011. For 2015, the slope was even further improved, from 0.05 (SMOS) to 0.44 (linear mode). As mentioned in Section 2, the study areas in 2015 contain two regions in the irrigated area and just one in the non-irrigated one, as opposed to two in 2011. This could possibly explain the better performance in terms of slope obtained, as DISPATCH is well suited to detect well rainfall or irrigation events. In the case of Algerri-Balaguer, the slope has increased from -0.49 (SMOS) to 0.44 (linear mode) and -0.14 (nonlinear mode), respectively. As for MOR3, the slope has increased slightly from 0.52 (SMOS) to 0.58 and 0.61 (linear and nonlinear modes).

In terms of bias, the values remain similar over Urgell, around $-0.100 \mathrm{~m}^{3} / \mathrm{m}^{3}$ for the 2011 period. For the 2015 period, the bias slightly decreases from $-0.079 \mathrm{~m}^{3} / \mathrm{m}^{3}$ (SMOS and DISPATCH nonlinear mode) to $-0.041 \mathrm{~m}^{3} / \mathrm{m}^{3}$ (linear mode). In the case of Algerri-Balaguer, the bias was slightly reduced from $-0.138 \mathrm{~m}^{3} / \mathrm{m}^{3}$ (SMOS) to $-0.114 \mathrm{~m}^{3} / \mathrm{m}^{3}$ (linear mode).

As for the Moroccan site, very low bias values have been obtained. This might be explained by the fact that the in situ SM values are very low, as the location of the sensor is close to a desert area. In this area, what SMOS might pick up could be mostly the instrument noise, with a low reported value.

The uRMSE for Urgell 2011 and 2015 report roughly the same value: $0.092-0.102 \mathrm{~m}^{3} / \mathrm{m}^{3}$. For the Algerri-Balaguer region, the uRMSE obtained is roughly around $0.060 \mathrm{~m}^{3} / \mathrm{m}^{3}$ in all cases. As for 
MOR3, very low values are obtained, around $0.030 \mathrm{~m}^{3} / \mathrm{m}^{3}$, for SMOS and DISPATCH linear/nonlinear modes. The low values are explained by the low values of the in situ measurements and of SMOS SM registered over the area.

\subsubsection{Yearly Calibration Mode}

When comparing the linear and nonlinear models in the yearly calibration mode, the nonlinear model outperforms the linear one. In fact, it gives the best results amongst all model-calibration mode combinations.

Correlations are improved with the nonlinear model to 0.54 for Urgell 2011 and to 0.57 for Urgell 2015. An improvement is also seen for Algerri-Balaguer, obtaining a 0.47 correlation coefficient, as opposed to -0.08 obtained in the linear mode. A similar correlation coefficient as the ones obtained with the daily calibration mode is obtained for MOR3 with the nonlinear model, 0.34 .

The highest slope of linear regression, for all sites, is obtained with the nonlinear model: 0.36 (Urgell 2011), 0.47 (Urgell 2015), 1.16 (Algerri-Balaguer) and 0.75 (MOR3), values which are also better than the ones obtained with the daily calibration mode.

In terms of bias, lower values are obtained with the nonlinear model: $-0.031 \mathrm{~m}^{3} / \mathrm{m}^{3}$ as opposed to $-0.079 \mathrm{~m}^{3} / \mathrm{m}^{3}$ (Urgell 2015), $-0.063 \mathrm{~m}^{3} / \mathrm{m}^{3}$ as opposed to $-0.153 \mathrm{~m}^{3} / \mathrm{m}^{3}$ (Algerri-Balaguer). These values also correspond to the lowest values obtained for the respective sites out of all registered values.

Lower values of uRMSE are obtained by using the nonlinear model, with values remaining roughly between $0.030-0.070 \mathrm{~m}^{3} / \mathrm{m}^{3}$.

Besides its capability of better capturing the nonlinearity effects inherent to the SEE(SM) relationship, the nonlinear model with a multi-date calibration performs better than with the daily calibration mode. This can be attributed to the temporal dynamics of the MODIS-observed SEE used to calibrate the nonlinear model being better suited to characterize the $S M_{c}$ parameter in Equation (5). This renders the results more robust, a fact corroborated by the slope of the linear regression systematically improving. In the case of the linear mode, the uncertainties in the retrieved daily $S M_{p}$ parameter in Equation (3), which can be partly due to variations in the SEE and/or errors in the SMOS SM, seem to propagate in the multi-date calibration, as $S M_{p}$ is set to the average of daily $S M_{p}$ values. Small uncertainties in the model parameterization may have a large impact on the predictions, which could partly explain the poor results obtained with the linear mode with a multi-date calibration. This is not as evident when using the linear model on a daily scale, since there seem to be significant compensation effects between daily SEE and daily $S M_{p}$ variations.

\subsection{General Discussion}

Two types of validations have been performed: a spatial validation and a spatio-temporal validation. In terms of spatial validation, DISPATCH clearly captures the spatial variability within the Urgell study area, distinguishing between the dryland and irrigated areas. The nonlinear model with a multi-date calibration systematically performs better than any other. In the case of Urgell 2011, the range of correlation coefficients is improved from [ $-0.26 ; 0.49]$ (nonlinear model, daily calibration) to [ $-0.23 ; 0.57]$. In the same manner, the higher end of the range of the slope of linear regression is also improved from 0.25 (nonlinear model, daily calibration) to 0.42 . In the case of Urgell 2015, the range of the correlation coefficient improves from [0.40; 0.75] (linear model, daily calibration) to [0.57; 0.81$]$.

Looking at the temporal validation, when comparing the daily versus multi-date calibration methodologies, the linear model performs better with the daily mode in the case of Urgell 2015 (corroborating the results obtained for the spatial validation), while the nonlinear model performs better with the multi-date mode. This might be explained by the fact that the nonlinear model is more sensitive to daily changes, while the linear one proves to be more robust. This is consistent with previous studies that have recommended the use of the linear model for DISPATCH applications at $1 \mathrm{~km}$ resolution $[15,18,48]$. In the multi-date mode however, the nonlinear model outperforms the 
linear model. When comparing the linear and the nonlinear modes, one can conclude that the nonlinear SEE model, with a multi-date calibration, significantly improves the correlation coefficient and the slope of the linear regression, as well as improving (even if slightly), or maintaining, the other statistical parameters. For example, the slope is improved from -0.14 to 1.16 over Algerri-Balaguer, while the correlation coefficient increases from -0.08 to 0.47 . The values of the uRMSE are systematically lower, regardless of the study area, when using the nonlinear model with a multi-date calibration. Better results are reported in nonlinear mode with multi-date calibration than in linear mode. In fact, in the nonlinear mode, the partial derivative of SM with respect to SEE is diminished in the lower SM ranges and increased in the higher SM ranges. This entails an overall better precision and accuracy of the corresponding disaggregated products when compared to the in situ measurements. In particular, a small derivative in the lower SM ranges means that the $1 \mathrm{~km} \mathrm{SM}$ data is approximately equal to the LR SM. In [18], a comparison has also been made at HR $(\sim 100 \mathrm{~m})$ resolution between the linear model and a different nonlinear model (with a daily calibration), and it was concluded that the nonlinear model is a more adequate choice as it increases the slope of the linear regression between downscaled products and in situ measurements, thus improving the spatial representativeness of SM. The rationale is that the range of SM values within an LR pixel generally increases with the target spatial resolution, and that the nonlinearity effects are more prominent for larger SM spatial variabilities.

An important aspect to mention is the negative values of disaggregated SM when using the nonlinear SEE(SM) model in the downscaling relationship. If we assume that the disaggregation is efficient, then this could point out that SMOS underestimates SM in very dry areas (with SM close to zero). Various calibration and validation studies of SMOS SM products have reported a negative bias [68-71]. The bias in the retrieved SM is inflicted by biases in the brightness temperatures, which could be provoked by the RFI for instance. According to [72], a positive bias in the observed brightness temperature would imply a negative bias in the SM products. Since SMOS SM is used when calibrating the $S M_{c}$ parameter, the parameter retrieval is also affected by the negative bias. The downscaled SM data obtained in the nonlinear mode is thus affected by both potential biases in the retrieved $S M_{\mathcal{C}}$ values, as well as the negative bias in SMOS data.

It is satisfying to observe that a nonlinear representation of SEE, which is widely acknowledged by a number of in situ and modeling studies, provides systematic better results in terms of SEE-based disaggregation. The key, however, is to develop a calibration strategy adapted to the multi-sensor/multi-resolution data, to their respective uncertainty and to the nature of the model used. Note that the multi-date calibration of each model can be applied over any given period of time, it does not have to be one year only as in our study. However, the multi-date calibration implies a certain latency in the DISPATCH products. In the case of the linear model with a multi-date calibration, the $S M_{p}$ parameter is calibrated as the average of daily $S M_{p}$ values (as previously stated). This implies DISPATCH has to be first run in the daily mode in order to obtain daily $S M_{p}$ values. Similarly, the nonlinear model is calibrated on a muli-date basis using daily $S E E_{L R}$ data. This also implies DISPATCH has to be first run in daily mode in order to obtain these datasets. Nevertheless, in the case of the nonlinear model, it has been shown that a multi-date calibration proves to be more robust than a daily calibration. Future studies can study the impact of the window considered for the calibration. In fact, choosing a model is also driven by the calibration strategy that can be afforded by this model using the data available at the application scale.

\section{Summary and Conclusions}

DISPATCH provides $1 \mathrm{~km}$ resolution SM data from $40 \mathrm{~km}$ resolution SMOS and $1 \mathrm{~km}$ resolution MODIS data by combining MODIS-derived SEE estimates at HR and a SEE(SM) model implemented at LR. The SEE model is self-calibrated from MODIS and SMOS data alone. In the current DISPATCH version, the SEE(SM) model is calibrated at a daily scale from quasi-simultaneous MODIS and SMOS observations by assuming a linear SEE representation. 
This paper introduces a nonlinear SEE(SM) model in the downscaling relationship. Two calibrations are tested for each SM-based SEE model: on a daily basis and on a multi-date basis.

The approaches are tested by comparing the disaggregated SM values with in situ measurements over two mixed dry and irrigated areas in Catalonia (Spain)—spanning 2011 and 2015 (Urgell area) and 2017-2018 (Algerri-Balaguer), and over a dry area in Morocco (MOR3) in 2016-2017. Two types of validations are performed: a spatial validation and a spatio-temporal validation.

When comparing the two models in the daily calibration mode (both for the temporal as well as the spatial validation), the linear model gives better results in the case of Urgell 2015, improving the slope of linear regression, correlation coefficient and bias values. The correlation coefficient is equal to 0.44 (temporal validation), while the slope of the linear regression is increased to 0.44 (temporal validation).

The integration of a nonlinear SEE(SM) model with a multi-date calibration systematically improves the statistics over all sites (for both the spatial and the temporal validation). The temporal correlation is increased to 0.57 and 0.47 for Urgell 2015 and Algerri-Balaguer, while the slope of linear regression is 0.47 and 1.16, respectively. The introduction of a nonlinear model with multi-date calibration systematically lowers the values of the uRMSE, regardless of the study area.

The low correlations obtained over all Spanish sites could also partly be explained by some small RFI (Radio Frequency Interference) sources detected within the area. An analysis of the SMOS products was performed over the Spanish sites and it has shown high values of RFI. This leads to erroneous measurements by SMOS, which propagates in the downscaled products, regardless of the SM-based SEE model and of the calibration used.

Keeping in mind that the calibration strategy is to be adapted to the multi-sensor/multi-resolution data and to the SEE(SM) model used, the nonlinear SEE(SM) model has proven to perform significantly better under various conditions, with more robust disaggregated SM products being obtained.

The SEE modeling based on the nonlinear SM model, with a multi-date calibration, could be integrated into the CATDS-Centre Aval de Traitement des Données SMOS [15] as a future new product, into existing evapotranspiration models, which are based on a combination of thermal and microwave data $[73,74]$, as well as into a new stepwise disaggregation approach using DISPATCH at an intermediate spatial resolution [65].

Author Contributions: Data curation, V.-G.S., J.C. and J.M.V.; formal analysis, V.-G.S.; funding acquisition, O.M. and M.-J.E.; investigation, V.-G.S.; methodology, V.-G.S. and O.M.; project administration, O.M. and M.-J.E.; software, V.-G.S. and B.M.; supervision, O.M.; validation, V.-G.S.; writing-original draft, V.-G.S.; writing-review and editing, V.-G.S., O.M., M.-J.E., B.M., J.M.V. and S.E.-R. All authors have read and agreed to the published version of the manuscript.

Funding: This research was funded by the Torrres Quevedo program of the Spanish Science Ministry, MICINN (grant number PTQ-16-08766).

Acknowledgments: This study was supported by the French Agence Nationale de la Recherche (MIXMOD-E project, ANR-13-JS06-003-01), the European Commission ERA-NET COFUND WATERWORKS 2015 Programme (Water4Ever project), and the European Commission Horizon 2020 Programme for Research and Innovation (H2020) in the context of the Marie Sklodowska-Curie Research and Innovation Staff Exchange (RISE) action (ACCWA project, grant agreement no:823965).

Conflicts of Interest: The authors declare no conflict of interest.

\section{References}

1. Daly, E.; Porporato, A. A Review of Soil Moisture Dynamics: From Rainfall Infiltration to Ecosystem Response. Environ. Eng. Sci. 2005. [CrossRef]

2. Guérif, M.; Duke, C. Adjustment procedures of a crop model to the site specific characteristics of soil and crop using remote sensing data assimilation. Agric. Ecosyst. Environ. 2000. [CrossRef]

3. Chen, F.; Crow, W.; Starks, P.; Moriasi, D. Improving hydrologic predictions of a catchment model via assimilation of surface soil moisture. Adv. Water Resour. 2011, 34, 526-536. [CrossRef]

4. Dirmeyer, P. Using a global soil wetness dataset to improve seasonal climate simulation. J. Clim. 2000, 13, 2900-2922. [CrossRef] 
5. Douville, H. Relevance of soil moisture for seasonal atmospheric predictions: Is it an initial value problem? Clim. Dyn. 2004, 22, 429-446. [CrossRef]

6. Entekhabi, D.; Eagleson, P. Solving the inverse problem for soil moisture and temperature profiles by sequential assimilation of multifrequency remotely sensed observationsLand surface hydrology parameterization for atmospheric General Circulation models including subgrid scale spatial variability. J. Clim. 1989, 2, 816-831.

7. Famiglietti, J.; Wood, E. Effects of Spatial Variability and Scale on Areally Averaged Evapotranspiration. Water Resour. Res. 1995, 31, 699-712. [CrossRef]

8. Crow, W.T.; Wood, E.F. The value of coarse-scale soil moisture observations for regional surface energy balance modeling. J. Hydrometeorol. 2002, 178, 241-255. [CrossRef]

9. Kerr, Y.H. Soil moisture from space: Where are we? Hydrogeol. J. 2007, 15, 117-120. [CrossRef]

10. Wagner, W.; Bloschl, G.; Pampaloni, P.; Calvet, J.C.; Bizzari, B.; Wigneron, J.P.; Kerr, Y. Operational readiness of microwave remote sensing of soil moisture for hydrologic applications. Nord. Hydrol. 2007, 38, 1-20. [CrossRef]

11. Njoku, E.; Jackson, T.; Lakshmi, V.; Chan, T.; Nghiem, S. Soil moisture retrieval from AMSR-E. IEEE Trans. Geosci. Remote Sens. 2003, 41, 215-229. [CrossRef]

12. Kerr, Y.H.; Waldteufel, P.; Richaume, P.; Wigneron, J.P.; Ferrazzoli, P.; Mahmoodi, A.; Al Bitar, A.; Cabot, F.; Gruhier, C.; Leroux, D.; et al. The SMOS soil moisture retrieval algorithm. IEEE Trans. Geosci. Remote Sens. 2012. [CrossRef]

13. Wood, E. Effects of soil moisture aggregation on surface evaporation fluxes. J. Hydrometeorol. 1997, 190, 397-412.

14. Walker, J.P.; Houser, P. Requirements of a global near-surface soil moisture satellite mission: Accuracy, repeat time, and spatial resolution. Adv. Water Resour. 2004, 27, 785-800. [CrossRef]

15. Molero, B.; Merlin, O.; Malbéteau, Y.; Bitar, A.A.; Cabot, F.; Stefan, V.; Bacon, S.; Kerr, Y.; Bindlish, R.; Jackson, T. New SMOS disaggregated soil moisture product at $1 \mathrm{~km}$ resolution: Processor overview and first validation results. Remote Sens. Environ. 2016, 180, 361-376. [CrossRef]

16. Peng, J.; Loew, A.; Merlin, O.; Verhoest, E. A review of spatial downscaling of satellite remotely sensed soil moisture. Rev. Geophys. 2017, 55. [CrossRef]

17. Sabaghy, S.; Walker, J.; Renzullo, L.; Jackson, T. Spatially enhanced passive microwave derived soil moisture: Capabilities and opportunities. Remote Sens. Environ. 2018. [CrossRef]

18. Merlin, O.; Escorihuela, M.J.; Mayoral, M.A.; Hagolle, O.; Al Bitar, A.; Kerr, Y. Self-calibrated evaporation-based disaggregation of SMOS soil moisture: An evaluation study at $3 \mathrm{~km}$ and $100 \mathrm{~m}$ resolution in Catalunya, Spain. Remote Sens. Environ. 2013, 130, 25-38. [CrossRef]

19. El Hajj, M.; Baghdadi, N.; Bazzi, H.; Zribi, M. Penetration analysis of SAR signals in the C and L bands for wheat, maize, and grasslands. Remote Sens. 2018, 11, 31. [CrossRef]

20. El Hajj, M.; Baghdadi, N.; Zribi, M. Comparative analysis of the accuracy of surface soil moisture estimation from the C-and L-bands. J. Appl. Earth Obs. Geoinf. 2019, 82, 101888. [CrossRef]

21. Sekertekin, A.; Murat Marangoz, A.; Abdikan, S. ALOS-2 and Sentinel-1 SAR data sensitivity analysis to surface soil moisture over bare and vegetated agricultural fields. Comput. Electron. Agric. 2020, 171, 105303. [CrossRef]

22. Zribi, M.; Muddu, S.; Bousbih, S.; Al Bitar, A.; Kumar Tomer, S.; Baghdadi, N.; Bandyopadhyay, S. Analysis of L-band SAR data for soil moisture estimations over agricultural areas in the tropics. Remote Sens. 2019, 11, 1122. [CrossRef]

23. Zhan, X.; Miller, S.; Chauhan, N.; DI, L.; Ardanuy, P. Soil Moisture Visible/Infrared Radiometer Suite Algorithm Theoretical Basis Document; Raytheon Systems Company: Lanham, MD, USA, 2002.

24. Carlson, T.N.; Gillies, R.R.; Perry, E.M. A method to make use of thermal infrared temperature and NDVI measurements to infer soil water content and fractional vegetation cover. Remote Sens. Rev. 1994, 52, 45-59. [CrossRef]

25. Fang, B.; Lakshmi, V.; Bindlish, R.; Jackson, T.; Cosh, M.; Basara, J. Passive Microwave Soil Moisture Downscaling Using Vegetation Index and Skin Surface Temperature. Vadose Zone J. 2013, 12. [CrossRef]

26. Moran, M.S.; Clarke, T.R.; Inoue, Y.; Vidal, A. Estimating crop water deficit using the relation between surface-air temperature and spectral vegetation index. Remote Sens. Environ. 1994, 49, 246-263. [CrossRef] 
27. Carlson, T. An overview of the 'Triangle Method' for estimating surface evapotranspiration and soil moisture from satellite imagery. Sensors 2007, 7, 1612-1629. [CrossRef]

28. Petropoulos, G.; Carlson, T.; Wooster, M.; Islam, S. A review of Ts/VI remote sensing based methods for the retrieval of land surface energy fluxes and soil surface moisture. Prog. Phys. Geogr. 2009, 33, 224-250. [CrossRef]

29. Tang, R.; Li, Z.L.; Tang, B. An application of the Ts-VI method with enhanced edges determination for evapotranspiration estimation from MODIS data in arid and semi-arid regions: Implementation and validation. Remote Sens. Environ. 2010, 114, 540-551. [CrossRef]

30. Stefan, V.; Merlin, O.; Er-Raki, S.; Escorihuela, M.; Khabba, S. Consistency between in situ, model-derived and image-based soil temperature endmembers: Towards a robust data-based model for multi-resolution monitoring of crop evapotranspiration. Remote Sens. 2015, 7, 10444-10479. [CrossRef]

31. Sabaghy, S.; Walker, J.; Renzullo, L.; Akbar, R.; Chan, S.; Chaubell, J.; Das, N.; Dunbar, R.S.; Entekhabi, D.; Gevaert, A.; et al. Comprehensive analysis of alternative downscaled soil moisture products. Remote Sens. Environ. 2020, 239. [CrossRef]

32. Kim, J.; Hogue, T.S. Improving spatial soil moisture representation through integration of AMSR-E and MODIS products. IEEE Trans. Geosci. Remote Sens. 2012, 50, 446-460. [CrossRef]

33. Peng, J.; Loew, A.; Zhang, S.; Wang, J.; Niesel, J. Spatial downscaling of satellite soil moisture data using a Vegetation Temperature Condition Index. IEEE Trans. Geosci. Remote Sens. 2016, 54, 1-9. [CrossRef]

34. Fang, B.; Lakshmi, V. Soil moisture at watershed scale: Remote sensing techniques. J. Hydrol. 2014, 512, 258-272. [CrossRef]

35. Song, C.; Jia, L.; Menenti, M. Retrieving high-resolution surface soil moisture by downscaling AMSR-E brightness temperature using MODIS LST and NDVI data. IEEE J. Sel. Top. Appl. Earth Obs. Remote Sens. 2014, 7, 935-942. [CrossRef]

36. Chauhan, N.S.; Miller, S.; Ardanuy, P. Spaceborne soil moisture estimation at high resolution: A microwave-optical/IR synergistic approach. Int. J. Remote Sens. 2003, 24, 4599-4622. [CrossRef]

37. Piles, M.; Camps, A.; Vall-llossera, M.; Corbella, I.; Panciera, R.; Rüdiger, C.; Kerr, Y.H.; Walker, J.P. Downscaling SMOS-derived soil moisture using MODIS visible/infrared data. IEEE Trans. Geosci. Remote Sens. 2011, 49, 3156-3166. [CrossRef]

38. Piles, M.; Petropoulos, G.; Sánchez, N.; Gonzalez-Zamora, A.; Ireland, G. Towards improved spatio-temporal resolution soil moisture retrievals from the synergy of SMOS and MSG SEVIRI spaceborne observations. Remote Sens. Environ. 2016, 180, 403-417. [CrossRef]

39. Sánchez-Ruiz, S.; Piles, M.; Sánchez, N.; Martínez-Fernández, J.; Vall-llosera, M.; Camps, A. Combining SMOS with visible and near/shortwave/thermal infrared satellite data for high resolution soil moisture estimates. J. Hydrol. 2014, 516, 273-283. [CrossRef]

40. Portal, G.; Vall-llossera, M.; Piles, M.; Camps, A.; Chaparro, D.; Pablos, M.; Rossato, L. A Spatially Consistent Downscaling Approach for SMOS Using an Adaptive Moving Window. JSTARS 2018, 11. [CrossRef]

41. Crago, R.; Brutsaert, W. Daytime evaporation and the self-preservation of the evaporative fraction during the daytime. J. Hydrol. 1996, 178, 241-255. [CrossRef]

42. Gentine, P.; Entekhabi, D.; Chehbouni, A.; Boulet, G.; Duchemin, B. Analysis of evaporative fraction diurnal behaviour. Agric. For. Meteorol. 2007, 143, 13-29. [CrossRef]

43. Nishida, K.; Nemani, R.R.; Glassy, J.M.; Running, S.W. Development of an evapotranspiration index from Aqua/MODIS for monitoring surface moisture status. IEEE Trans. Geosci. Remote Sens. 2003, 41, $493-501$. [CrossRef]

44. Wen, F.; Zhao, W.; Wang, Q.; Sánchez, N. A Value-Consistent Method for Downscaling SMAP Passive Soil Moisture With MODIS Products Using Self-Adaptive Window. IEEE Trans. Geosci. Remote Sens. 2020, 58, 913-924. [CrossRef]

45. Piles, M.; Sánchez, N.; Vall-llosera, M.; Camps, A.; Martínez, J.; Gonzalez-Gambau, V. A downscaling approach for SMOS land observations: Evaluation of high-resolution soil moisture maps over the Iberian Peninsula. IEEE J. Sel. Top. Appl. Earth Obs. Remote Sens. 2014, 7, 3845-3857. [CrossRef]

46. Merlin, O.; Walker, J.P.; Chehbouni, A.; Kerr, Y. Towards deterministic downscaling of SMOS soil moisture using MODIS derived soil evaporative efficiency. Remote Sens. Environ. 2008, 112, 3935-3946. [CrossRef]

47. Merlin, O.; Rüdiger, C.; Al Bitar, A.; Richaume, P.; Walker, J.; Kerr, Y. Disaggregation of SMOS soil moisture in southeastern Australia. IEEE Trans. Geosci. Remote Sens. 2012, 50, 1556-1571. [CrossRef] 
48. Malbéteau, Y.; Merlin, O.; Molero, B.; Rüdiger, C.; Bacon, S. DisPATCh as a tool to evaluate coarse-scale remotely sensed soil moisture using localized in situ measurements: Application to SMOS and AMSR-E data in Southeastern Australia. Int. J. Appl. Earth Obs. Geoinf. 2016, 45, 221-234. [CrossRef]

49. Escorihuela, M.J.; Merlin, O.; Stefan, V.; Moyano, G.; Ali Eweys, O.; Zribi, M.; Kamara, S.; Salem Benahi, A.; Abdallahi Babah Ebbe, M.; Chihrane, J.; et al. SMOS based high resolution soil moisture estimates for desert locust preventive management. Remote Sens. Appl. Society Environ. 2018, 11, 140-150. [CrossRef]

50. Noilhan, J.; Planton, S. A simple parameterization of land surface processes for meteorological models. Mon. Weather Rev. 1989, 117, 536-549. [CrossRef]

51. Komatsu, T.S. Towards a robust phenomenological expression of evaporation efficiency for unsaturated soil surfaces. J. Appl. Meteorol. 2003, 42, 1330-1334. [CrossRef]

52. Merlin, O.; Stefan, V.; Amazirh, A.; Chanzy, A.; Ceschia, E.; Beringer, T.T.; Gentine, P.; Er-Raki, S.; Bircher, S.; Khabba, S. An improved algorithm for disaggregating microwave-derived soil moisture based on red, near-infrared and thermal-infrared data. Water Resourc. Res. 2016. [CrossRef]

53. Merlin, O.; Al Bitar, A.; Walker, J.P.; Kerr, Y. An improved algorithm for disaggregating microwave-derived soil moisture based on red, near-infrared and thermal-infrared data. Remote Sens. Environ. 2010, 114, 2305-2316. [CrossRef]

54. Zhao, W.; Li, A. A downscaling method for improving the spatial resolution of AMSR-E derived soil moisture product based on MSG-SEVIRI data. Remote Sens. 2013, 5, 6790-6811. [CrossRef]

55. Saxton, K.; Rawls, W.; Romberger, J.; Papendick, R. Estimating Generalized Soil-water Characteristics from Texture. Soil Sci. Soc. Am. J. 1986, 50, 1031-1036. [CrossRef]

56. Merlin, O.; Rüdiger, C.; Richaume, P.; Al Bitar, A.; Mialon, A.; Walker, J.P.; Kerr, Y. Disaggregation as a top-down approach for evaluating $40 \mathrm{~km}$ resolution $\mathrm{SMOS}$ data using point-scale measurements: Application to AACES-1. In Proceedings of the SPIE, Remote Sensing of Agriculture, Ecosystems, and Hydrology XII, San Diego, CA, USA, 28 June 2010. [CrossRef]

57. Wan, Z.; Hook, S.; Hulley, G. MOD11A1 MODIS/Terra Land Surface Temperature/Emissivity Daily L3 Global 1 km SIN Grid V006. NASA EOSDIS Land Process. DAAC 2015. [CrossRef]

58. Wan, Z.; Hook, S.; Hulley, G. MYD11A1 MODIS/Aqua Land Surface Temperature/Emissivity Daily L3 Global $1 \mathrm{~km}$ SIN Grid V006. NASA EOSDIS Land Process. DAAC 2015. [CrossRef]

59. Didan, K. MOD13A2 MODIS/Terra Vegetation Indices 16-Day L3 Global 1 km SIN Grid V006. NASA EOSDIS Land Process. DAAC 2015. [CrossRef]

60. Budyko, M. Heat Balance of the Earth's Surface; Gidrometeoizdat: Leningrad, Russia, 1956.

61. Manabe, S. Climate and the ocean circulation. I. The atmospheric circulation and the hydrology of the Earth's surface. Mon. Weather. Rev. 1969, 97, 739-774. [CrossRef]

62. Lee, T.J.; Pielke, R.A. Estimating the soil surface specific humidity. J. Appl. Meteorol. 1992, 31, 480-484. [CrossRef]

63. Chanzy, A.; Bruckler, L. Significance of soil surface moisture with respect to daily bare soil evaporation. Water Resour. Res. 1993, 29, 1113-1125. [CrossRef]

64. Merlin, O.; Al Bitar, A.; Rivalland, V.; Béziat, P.; Ceschia, E.; Dedieu, G. An analytical model of evaporation efficiency for unsaturated soil surfaces with an arbitrary thickness. J. Appl. Meteorol. Clim. 2011, 50, 457-471. [CrossRef]

65. Ojha, N.; Merlin, O.; Molero, B.; Suere, C.; Olivera-Guerra, L.; Ait-Hssaine, B.; Amazirh, A.; Bitar, A.A.; Escorihuela, M.J.; Er-Raki, S. Stepwsie Disaggregation of SMAP Soil Moisture at $100 \mathrm{~m}$ Resolution Using Landsat-7/8 Data and a Varying Intermediate Resolution. Remote Sens. 2019, 11. [CrossRef]

66. Merlin, O.; Malbéteau, Y.; Notfi, Y.; Bacon, S.; Er-Raki, S.; Khabba, S.; Jarlan, L. Performance Metrics for Soil Moisture Downscaling Methods: Application to DISPATCH Data in Central Morocco. Remote Sens. 2015, 7, 3783-3807. [CrossRef]

67. Al Bitar, A.; Mialon, A.; Kerr, Y.H.; Cabot, F.; Richaume, P.; Jacquette, E.; Quesney, A.; Mahmoodi, A.; Tarot, S.; Parrens, M.; et al. The global SMOS Level 3 daily soil moisture and brightness temperature maps. Earth Sys. Sci. Data 2017, 9, 293-315. [CrossRef]

68. Collow, T.; Robock, A.; Basara, J.B.; Illston, B. Evaluation of SMOS retrievals of soil moisture over the central United States with currently available in situ observations. J. Geophys. Res. 2012, 117. [CrossRef] 
69. Zeng, J.; Zhen, L.; Chen, Q.; Bi, H.; Qiu, J.; Zou, P. Evaluation of remotely sensed and reanalysis soilmoisture products over the Tibetan Plateau using in-situ observationss. Remote Sens. Environ. 2015, 163, 91-110. [CrossRef]

70. Al Bitar, A.; Leroux, D.J.; Kerr, Y.; Merlin, O.; Richaume, P.; Sahoo, A.; Wood, E. Evaluation of SMOS Soil Moisture Products Over Continental U.S. Using the SCAN / SNOTEL Network. IEEE Trans. Geosci. Remote Sens. 2012, 50, 1572-1586. [CrossRef]

71. Djamai, N.; Magagi, R.; Goita, K.; Merlin, O.; Kerr, Y.; Roy, A. A combination of DISPATCH downscaling algorithm with CLASS land surface scheme for soil moisture estimation at fine scale during cloudy days. Remote Sens. Environ. 2016, 184, 1-14. [CrossRef]

72. Dente, L.; Su, Z.; Wen, J. Validation of SMOS Soil Moisture Products over the Maqu and Twente Regions. Sensors 2012, 12, 9965-9986. [CrossRef]

73. Ait Hssaine, B.; Merlin, O.; Rafi, Z.; Ezzahar, J.; Jarlan, L.; Khabba, S.; Er-Raki, S. Calibrating an evapotranspiration model using radiometric surface temperature, vegetation cover fraction and near-surface soil moisture. Agric. For. Meteorol. 2018, 256-257, 104-115. [CrossRef]

74. Ait Hssaine, B.; Merlin, O.; Ezzahar, J.; ojha, N.; Er-Raki, S.; Khabba, S. An evapotranspiration model self-calibrated from remotely-sensed surface soil moisture, land surface temperature and vegetation cover fraction: Application to disaggregated SMOS and MODIS data. Hydrol. Earth Syst. Sci. 2019. [CrossRef]

(C) 2020 by the authors. Licensee MDPI, Basel, Switzerland. This article is an open access article distributed under the terms and conditions of the Creative Commons Attribution (CC BY) license (http:/ / creativecommons.org/licenses/by/4.0/). 